\title{
Evaporation of J13 Water: Laboratory Experiments and Geochemical Modeling
}

\author{
N.D. Rosenberg \\ K.G. Knauss \\ M.J. Dibley
}

August 13, 1999

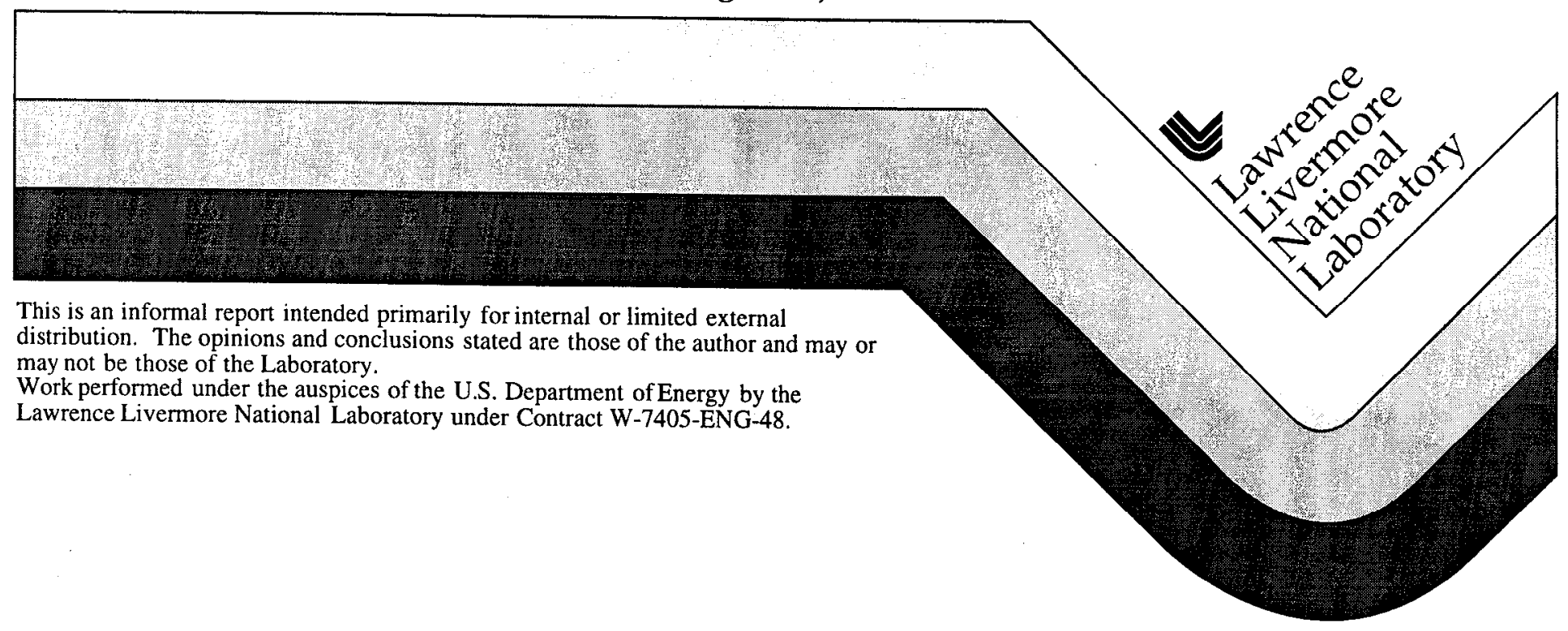




\section{DISCLAIMER}

This document was prepared as an account of work sponsored by an agency of the United States Government. Neither the United States Government nor the University of California nor any of their employees, makes any warranty, express or implied, or assumes any legal liability or responsibility for the accuracy, completeness, or usefulness of any information, apparatus, product, or process disclosed, or represents that its use would not infringe privately owned rights. Reference herein to any specific commercial product, process, or service by trade name, trademark, manufacturer, or otherwise, does not necessarily constitute or imply its endorsement, recommendation, or favoring by the United States Government or the University of California. The views and opinions of authors expressed herein do not necessarily state or reflect those of the United States Government or the University of California, and shall not be used for advertising or product endorsement purposes.

This report has been reproduced directly from the best available copy.

Available to DOE and DOE contractors from the Office of Scientific and Technical Information P.O. Box 62, Oak Ridge, TN 37831

Prices avaiłable from (423) 576-8401

Available to the public from the National Technical Information Service

U.S. Department of Commerce 5285 Port Royal Rd., Springfield, VA 22161 


\title{
Evaporation of J13 Water: Laboratory Experiments and Geochemical Modeling
}

\author{
N. D. Rosenberg, K. G. Knauss, M. J. Dibley
}

Geosciences and Environmental Technologies Division

Lawrence Livermore National Laboratory

Livermore, CA 94551

August 13, 1999 



\begin{abstract}
We report results from experiments on the evaporative chemical evolution of synthetic J13 water, representative of water from well J13, a common reference water in the Yucca Mountain Project. Data include anion and cation analysis and qualitative mineral identification for a series of open system experiments, with and without crushed tuff present, conducted at sub-boiling temperatures. $\mathrm{Ca}$ and $\mathrm{Mg}$ precipitated readily as carbonates and anions $\mathrm{Cl}, \mathrm{F}, \mathrm{NO}_{3}$ and $\mathrm{SO}_{4}$ remained in solution in nearly identical ratios. The $\mathrm{pH}$ stabilized at about 10 . After $\sim 1000 \mathrm{x}$ concentration, the minerals formed were amorphous silica, aragonite and calcite. The presence of tuff appears to have very little effect on the relative distribution of the anions in solution, except for possibly $\mathrm{F}$, which had a relatively lower concentration ratio. The Si was lower in the solutions with tuff present suggesting that the tuff enhances $\mathrm{SiO}_{2}$ precipitation. Even though the tools to model highly-concentrated salt solutions are limited, we compare our experimental results with the results of geochemical models, with (perhaps) surprising good results. In response to different assumed $\mathrm{CO}_{2}$ levels, $\mathrm{pH}$ varied, but anion concentrations were not greatly affected.
\end{abstract}




\section{Table of Contents}

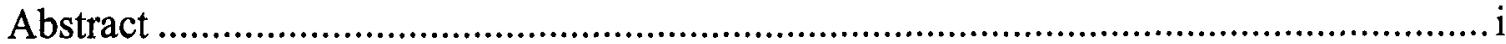

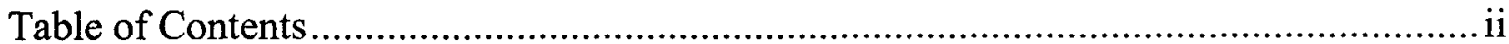

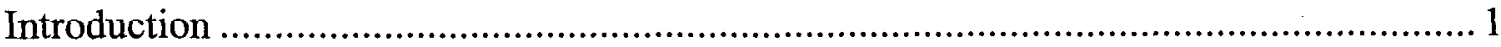

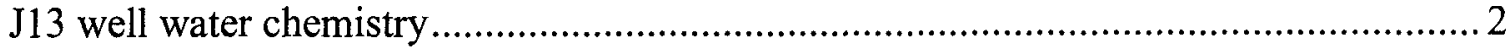

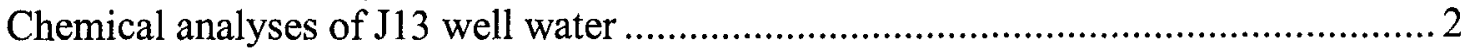

Making synthetic J13 well water in the laboratory ............................................. 2

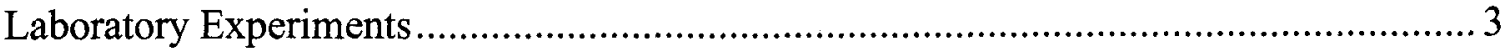

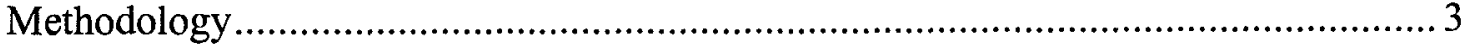

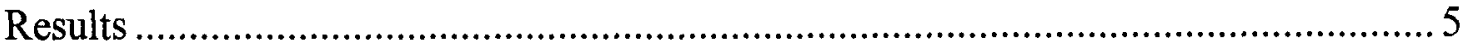

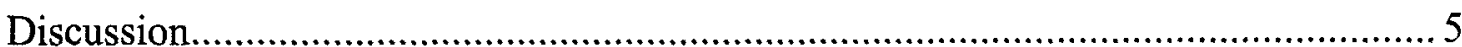

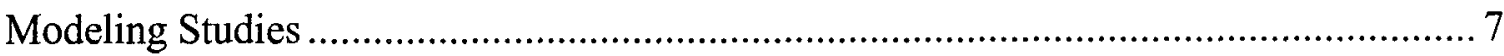

Limitations in modeling highly-concentrated salt solutions ............................... 7

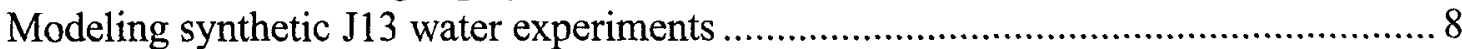

Application to near-field water at Yucca Mountain .......................................... 11

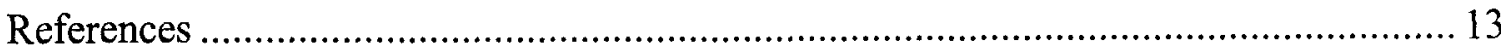

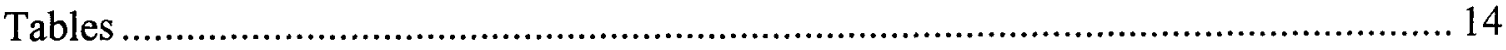

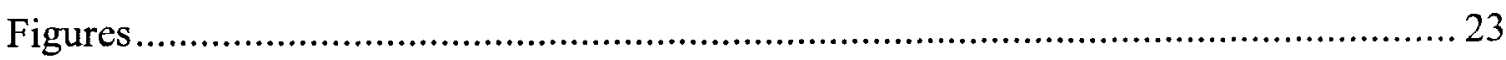




\section{Introduction}

The evaporative chemical evolution of near-field waters that might seep on to waste packages at the potential nuclcar waste repository at Yucca Mountain is an important factor in assessing repository performance and safety. Of particular interest with respect to waste package corrosion are $\mathrm{pH}$, concentrations of the anions (e.g., $\mathrm{Cl}, \mathrm{F}, \mathrm{NO}_{3}, \mathrm{SO}_{4}$ ), the oxygen potential (Eh), the nature of salts that may precipitate on the waste package surfaces, and the deliquescence point of those salts. The evaporative chemical evolution of near-field waters is also of concern in the assessment of potential radionuclide solubility and transport. With respect to these processes, the parameters $\mathrm{pH}, \mathrm{Eh}$, the concentration of specific metal-complexing anions, and total ionic strength are particularly important.

The chemical composition of near-field waters that might seep into drifts containing waste packages is the subject of much discussion within the Yucca Mountain Project. This report focuses on the evaporative chemical evolution of synthetic J13 water, representative of water from well J13 screened in the repository horizon rock, Topopah Springs Tuff (Harrar et al., 1990). J13 well water is a dilute $\mathrm{NaHCO}_{3}$ ground water similar to water produced from rhyolitic tuffs elsewhere on the Nevada Test Site and across the Western United States. J13 well water has been used as the basis for estimation of the chemistry of drift seepage water in a recent repository performance assessment (CRWMS M\&O, 1998). In addition, one of the solutions used for long-term corrosion testing of potential waste-package materials at LLNL was chosen to simulate J13 well water concentrated by a factor of 1000 (see McCright, 1998). Results from similar evaporation studies we have conducted on water representative of repository horizon porewater, which has a more $\mathrm{CaSO}_{4}$-rich composition (Sonnenthal, et al., 1998), will be presented in a separate report.

This report has three main sections. The first is a presentation of J13 well water chemistry and a discussion of making synthetic $\mathrm{J} 13$ well water in the laboratory. The second is a description of the evaporation experiments we conducted with synthetic $\mathrm{J13}$ water. These experiments include open bcaker expcriments, with and without crushed tuff present, conducted at temperatures of $75-85^{\circ} \mathrm{C}$. These experiments are meant to be representative of sub-boiling condulums in the repository, conditions which would likely exist both before and after the height of the thermal pulse caused by decaying radioactive waste.

The third section concerns the geochemical modeling of the evaporation of J13 well water. Mc first present a discussion of the limitations of our ability to model highly-concentrated salt solutions. As we emphasize in this section, in some cases we must rely for the moment on experimental data due to these limitations. We also compare our experimental data with model results to gain confidence in our models, which we then use to simulate possibly repositoryrelevant conditions that are beyond those of our experiments. 


\section{J13 well water chemistry}

\section{Chemical analyses of $J 13$ well water}

Water from well $\mathrm{J} 13$ became a de facto reference water for use in experimental work on the Yucca Mountain Project as many as 10 years before the summary report of Harrar et al. (1990). $\mathrm{J} 13$ well water is a dilute $\mathrm{NaHCO}_{3}$ groundwater. The mean concentration values of water collected from this well over the course of about 20 years of sampling arc reported in Table 1. These values represent the mean value of 15-20 analyses, each of which is the mean of replicate sampling in many cases. The well serves as the main water supply in the area of Yucca Mountain, is pumped frequently, and is capable of producing large amounts of water. It was therefore a natural choice as a reference water to represent waters produced from tuffaceous aquifers at Yucca Mountain.

\section{Making synthetic J13 well water in the laboratory}

Making a synthetic J13 water in the laboratory is not as straightforward as it may appear. The measured mean composition of $\mathrm{J} 13$ water is supersaturated with respect to the solubility of a number of minerals at $25^{\circ} \mathrm{C}$. These include many of the primary minerals in the tuff (e.g., quartz, albite, K-feldspar, cristobalite, ) as well as secondary minerals commonly found in the tuff (e.g., chalcedony, tridymite, kaolinite, illite, montmorillonite, anhydrite, clinoptilolite). Given the slow dissolution/precipitation kinetics at $25^{\circ} \mathrm{C}$, it is not possible to simply equilibrate distilled water with the tuff to "make" J13 water.

Unfortunately, adding readily soluble sources of the various components of J13 water (e.g., sodium metasilicate for $\mathrm{Si}$ ) to distilled water in the laboratory will not result in a solution with the exact composition of J13 water either. In order to add sufficient Si from that source, one also adds too much $\mathrm{Na}$ and increases the $\mathrm{pH}$ too much (the metasilicate solution has very high $\mathrm{NaOH}$, precisely because $\mathrm{Si}$ is relatively insoluble at neutral $\mathrm{pH}$ ). Therefore, synthetic J13 water approaches J13 well water in composition, but is not an exact match.

Note that the exact composition of the water used in many types of experiments (e.g., where water is heated in a closed system in the presence of rock) is often of little significance. Any dilute $\mathrm{NaHCO}_{3}$ water with the approximate composition of $\mathrm{J} 13$ water would yield identical results, because in these experiments the composition of the rock dominates the aqueous signal produced in the heated solution. For example, a synthetic $\mathrm{J} 13$ well water with lower $\mathrm{Si}$ concentration than J13 water may be of no consequence for once heated in the presence of tuff, any dilute water quickly attains a dissolved $\mathrm{Si}$ concentration dictated by cristobalite (the least stable silica polymorph present in the tuff) solubility control.

To make a synthetic J13 water for our experiments, we mixed a solution at room temperature, aiming for an approximate J13 composition (major ions), and stirred the solution for several days. The solution was then decanted to remove any undissolved reagents. The resulting solution was analyzed for the solutes of interest: $\mathrm{C}, \mathrm{Ca}, \mathrm{Cl}, \mathrm{F}, \mathrm{K}, \mathrm{Mg}, \mathrm{N}, \mathrm{Na}, \mathrm{S}, \mathrm{Si}$. The $\mathrm{pH}$ was also measured. The average composition of synthetic $\mathrm{J} 13$ water used in our experiments is given 
in Table 2. Throughout this report, when we refer to synthetic J13 water for a particular experiment, we use the actual composition for that specific experiment as determined by analysis, rather than the average reported in Table 2 or an estimate based on our J13 "recipe". The main difference between actual J13 well water and our synthetic J13 waters is that our synthetic solutions had a much lower Si content. Note that the concentration data reported in tables are rounded to the nearest significant figure. However, for data retrieval purposes, in spreadsheet calculations and plotting of derived values, more than the number of significant figures are included in the calculation to minimize rounding errors.

\section{Laboratory Experiments}

\section{Methodology}

Laboratory batch experiments were conducted at LLNL in 1998-1999. In the first two experiments, $30 \mathrm{~L}$ of synthetic $\mathrm{J13}$ water were evaporated down to $30 \mathrm{~mL}$ of solution, resulting in an evaporative concentration factor of approximately $1000 x$. In all experiments, actual concentration factors were estimated by mass measurements. We estimate that these concentration factors are accurate to approximately $10 \%$. The synthetic J13 solution was pumped into a $1 \mathrm{~L}$ pyrex beaker at a constant rate using a peristaltic pump while the sample evaporatively concentrated at $85^{\circ} \mathrm{C}$ with a hot plate as the heat source. The fluid delivery rate and heat flux were balanced to maintain constant temperature in the fluid contained within the beaker. Note that the temperature and heat flux used in these experiments are not intended to mimic exactly any one particular repository scenario. However, the assemblage of mineral phases that result from the cvaporation of this fluid is primarily controlled by precipitation kinetics at these temperatures, and therefore we expect the minerals assemblages we observe to be representative of repository conditions in general.

In the first experiment (evap1), detailed water chemistry measurements were made on the starting fluid ( 3 separate batches) and on a sample collected from the beaker after approximately $1000 x$ concentration. A small split of the solids that had precipitated were also removed at $1000 \mathrm{x}$ concentration for mineralogical analysis. The solution was then cvaporated completely to dryness and another small split of the solids was again removed for mineralogical analysis. The salts were then rewet with $200 \mathrm{~mL}$ of deionized water, evaporatively concentrated down to 100 $\mathrm{mL}$ at $75^{\circ} \mathrm{C}$ and the resulting solution was collected for detailed water chemistry analysis. The actual temperature and volumes used in the rewetting were not intended to represent any particular repository-specific scenario. Rather, they simply provide an empiric, if arbitrary, estimate of the effect of rewetting dry salts resulting from the complete evaporation of the synthetic $J 13$ water. This experiment was designed to investigate the evolving fluid chemistry and mineralogy as J13-like water is evaporatively concentrated and various minerals precipitate from solution as the fluid becomes supersaturated with respect to their solubility. In total, two aqueous samples and two solid samples were analyzed from this experiment, in addition to the starting fluid. 
In a second experiment (evap2), the experimental protocol was nearly identical to the first experiment (evap1) with the exception that the beaker contained $10 \mathrm{~g}$ of crushed Topopah Spring Tuff (Yucca Mountain Site Characterization Project Sample Management Facility Specimen ID $\# 00521699$ ). The grains were prepared by sieving the originally $<2 \mathrm{~mm}$ sample to $>0.5 \mathrm{~mm}$ in order to remove the fine fraction. The sized material was then washed three times in isopropanol, and the grains allowed to settle before decanting to remove adhering fine particles, and allowed to air dry. In this experiment we investigated the effect of the presence of tuff on the evolving fluid chemistry and mineralogy. This experiment also produced two aqueous samples and two solid samples for analysis, in addition to the starting fluid.

We measured the $\mathrm{pH}$ of the rewet samples for both the evap1 and evap2 experiments. Because solution $\mathrm{pH}$ is a key parameter, we conducted a third experiment (evap4) designed to focus on the short term evolution of $\mathrm{pH}$ over the course of an approximately 100 -fold concentration. We also sampled the fluid twice, at the start of the run and at the end, for complete chemical analysis. Note that in this experiment two data sets were combined: one from a four-day run with $\mathrm{pH}$ measured approximately every other hour and another from a very short run lasting only three hours that was measured approximately every 20 minutes or less. In the tables and figures for this experiment (evap4) the results from the two runs arc combincd in order of clapsed time. The starting solution for both data sets was the same.

The aqueous samples for cation and anion analyses were collected in plastic syringes. The aliquots were filtered through a $0.45 \mu \mathrm{m}$ filter ahead of a syringe that had been preloaded with deionized water. The fluid for cation analysis was then delivered into a plastic sample tube, further diluted with water and spiked with a concentrated acid solution. The total dilution was approximately 10 to 15 -fold in the sample submitted for cation analysis. The anion aliquot was collected in a similar manner (i.e., prefiltered and diluted with deionized water). However, the anion sample syringe was emptied into a glass sample vial. A small split of the anion sample was directly injected into an infared $\mathrm{CO}_{2}$ analyzer in the Geochemistry Laboratory, Building 281 at LLNL, to determine total $\mathrm{CO}_{2}$.

The following chemical analyses were performed:

- $\quad$ anions in solution

- cations in solution

- $\mathrm{pH}$ of solution

- minerals present in solids (qualitative).

The procedures for each of these analyses are briefly described below:

Two methods were used for anion analyses. The anions $\mathrm{Cl}, \mathrm{F}, \mathrm{SO}_{4}$ and $\mathrm{NO}_{3}$ were determined using ion chromatography (IC). The analytical protocol used also allows detection and quantification of several other anion analytes, but these four anions were the only ones (other than the carbonate species) present in these solutions. The sample aliquots had to be diluted considerably, owing to the low detection limits for this method. The carbonate anions $\left(\mathrm{HCO}_{3}\right.$ and $\mathrm{CO}_{3}$ ) were determined as total $\mathrm{CO}_{2}$ using an infared $\mathrm{CO}_{2}$ analyzer. 
The cation $(\mathrm{Na}, \mathrm{K}, \mathrm{Ca}, \mathrm{Mg}$ and $\mathrm{Si}$ ) concentrations were determined using inductively-coupled plasma emission spectrometry (ICP). These sample aliquots were also diluted considerably.

The $\mathrm{pH}$ measurements were accomplished by sampling into a plastic syringe and delivering the fluid, at approximately room temperature, gently into a plastic tube containing a calibrated combination $\mathrm{pH}$ electrode. The solution $\mathrm{pH}$ was determined using the NBS standard procedure. Note that the operational definition of measured $\mathrm{pH}$ (Bates, 1964) is intended to provide a convenient, reproducible method to measure $\mathrm{pH}$ potentiometrically in low ionic strength solutions using a cell consisting of a glass $\mathrm{H}^{+}$electrode and a reference electrode with a liquid junction. Strictly speaking, this limits $\mathrm{pH}$ measurement to solutions with less than 0.1 molal ionic strength (see Knauss et al., 1990, 1991 for further discussion), although useful measurement can be made up to seawater ionic strength, $\sim 0.7$ molal, with a little effort. For a water with the approximate ionic strength of $\mathrm{J} 13$ water, this limits measurement to something less than a 200 -fold concentration factor. In effect, this means that the measurement of $\mathrm{pH}$ in the starting solutions and throughout the evap4 experiment are accurate, but those made for the rewet samples of the evap1 and evap 2 runs are only approximations. We did not attempt to measure the $\mathrm{pH}$ of the $\sim 1000 \mathrm{x}$ samples, because the ionic strengths of those samples would exceed that specified by the NBS operational definition of measured $\mathrm{pH}$. In the future if accurate assessment of $\mathrm{H}^{+}$activity is required, other methods outlined in the cited references will be required.

The solids acquired during the these experiments (evapl and evap2) were analyzed using standard X-ray diffraction (XRD) methods. The primary purpose of the measurement was to identify the phases produced, so no quantification was attempted. The total mass of solids produced was also determined.

\section{Results}

The results of these experiments are shown in Tables $3-9$.

\section{Discussion}

Synthetic J13 water cvaporation experiment

The results of the experiment with synthetic J13 water alone (evap1) are presented graphically in Figs. 1 and 2. In Fig. 1, we show pie charts of the relative change in solution composition as one progresses from the starting synthetic J13 water to approximately 1000x (956x) sample to the rewet salts for the cations and anions, respectively. The histogram (Fig. 2) shows the absolute differences in ion concentration.

Several trends are readily apparent. After concentration approximately 1000 -fold, the solution is relatively devoid of both $\mathrm{Ca}$ and $\mathrm{Mg}$. This is accompanied by a decrease in $\mathrm{HCO}_{3}$ relative to all the other anions. This suggests removal of $\mathrm{Ca}$ and $\mathrm{Mg}$ as carbonates. The concentration factors 
for the other anions, $\mathrm{Cl}, \mathrm{F}, \mathrm{NO}_{3}$ and $\mathrm{SO}_{4}$, are nearly identical. The $\mathrm{pH}$ of the rewet solution is 10.59 .

The XRD analysis of the solids sampled from the run after $956 \mathrm{x}$ concentration (see Table 7) show the presence of amorphous silica, aragonite and calcite. Presumably, the $\mathrm{Mg}$ is going into a slightly disordered calcite, rather than forming a separate carbonate phase (e.g., magnesite). The minerals recovered after complete evaporation contain amorphous silica, aragonite, calcite, halite, niter, thermonatrite and, possibly, gypsum, anhydrite and hectorite. The last three minerals were not positive matches to the library patterns. The trends in solution chemistry for the evapl experiment as shown in Figs. 1-2 are compatible with the XRD results.

\section{Synthetic J13 water with crushed tuff evaporation experiment}

Pie charts of the relative solution composition for the evaporation experiments with Topopah Springs Tuff (evap2) are presented along with the results from the evaporation experiments without tuff in Fig. 1. The absolute value of solute concentrations are displayed in a histogram in Fig. 2.

Several trends are readily apparent. After concentration approximately 1000 -fold, the solution is relatively devoid of both $\mathrm{Ca}$ and $\mathrm{Mg}$ and the $\mathrm{HCO}_{3}$ concentration has decreased relative to all the other anions, suggesting as with the previous experiment, carbonate precipitation. The $\mathrm{Si}$ is also much lower in the concentrated evap2 solutions than the concentrated evap1 solutions, suggesting that the presence of the silicate and aluminosilicate minerals in the tuff enhances the precipitation of $\mathrm{SiO}_{2}$. The presence of tuff appears to have very little effect on the relative distribution of the anions, except for $\mathrm{F}$, which has a lower concentration ratio in both the $\sim 1000 \mathrm{x}$ and rewet solutions relative to the other anions in this case.

For the $\sim 1000 \mathrm{x}$ solution, the absolute amounts of the $\mathrm{Na}$ and $\mathrm{K}$ are lower in this experiment relative to the experiment with no crushed tuff present, even though the concentration factor is estimated to be greater in this case $(1114 \mathrm{x}$ vs. 956x). The $\mathrm{pH}$ of the rewet solution was measured at 9.99 , about a half $\mathrm{pH}$ unit lower than the experiment without tuff present. We note that the presence of the tuff allows for many more geochemical processes to occur (e.g., surface complexation) in addition to mineral dissolution and precipitation. It is possible that ion exchange reactions are responsible for the difference in $\mathrm{Na}, \mathrm{K}$ and $\mathrm{pH}$ trends in the evapl and evap2 experiments.

The XRD analysis of the solids sampled from the tuff plus water run after $1114 \mathrm{x}$ concentration (Table 8) show the presence of amorphous silica, aragonite, calcite, trona, thermonatrite, halite, anhydrite, smectite and niter. The minerals recovered after complete evaporation contain amorphous silica, aragonite, calcite, trona, thermonatrite, halite, anhydrite and smectite. The clays found in the 1000-fold sample were separated and found to be a mixture of dioctohedral smectite (probably montmorillonite) and trioctohedral smectite (hectorite, stevensite or saponite). The trends in solution chemistry for the evap2 experiment as shown in Figs. 1-2 are compatible with the XRD results. 


\section{Detailed short-term J13 water evaporation experiment}

Fig. 3 plots $\mathrm{pH}$ versus concentration factor for evap4, the short-term J13 evaporation experiment with water alone to a concentration factor of approximately $100 \mathrm{x}(157 \mathrm{x})$. The $\mathrm{pH}$ appears to stabilize at about 10 after an approximately 50 -fold concentration.

In a following section we will model the evaporative concentration of a water with the composition of synthetic J13 and compare it to the solution and solid analytical results just discussed.

\section{Modeling Studies}

\section{Limitations in modeling highly-concentrated salt solutions}

In an ideal thermodynamic system, each species is chemically independent from every other species (i.e., the molar free energy only depends on the mole fraction of the species). However, this is strictly true only in the limit of infinite dilution. As solutes are added and solution ionic strength increases, the solution becomes thermodynamically non-ideal and we have to account for this through the use of activity coefficients to "correct" the molar concentration. Various expressions for activity coefficients as functions of ionic strength have been developed. Two in particular have been coded into the geochemical models that are in general use, EQ3/6 (Wolery, 1998) and REACT (Bethke, 1998). These are the B-dot and Davies equations. Once the ionic strength of the evaporating solution gets much beyond that of seawater (about 0.7 molal), however, even these methods become imprecise.

The major limitation with modeling highly-concentrated salt solutions, however, is the limited choices of thermodynamic databases. Ideally, we would like to use a database that (1) includes all the aqueous species and minerals of interest, (2) is valid at high ionic strengths, and (3) is valid at the elevated temperatures. There are several commonly used thermodynamic databases used with geochemical models EQ3/6 (Wolery, 1998) and REACT (Bethke, 1998), but none has all of these desired features.

The most extensive thermodynamic database that permits calculations at elevated temperatures, EQ3/6's data0.com (now called data $0 . \mathrm{cmp}$ ) is only valid to an ionic strength of $0.7-1.0$ molal. Beyond this ionic strength,EQ3/6's data0.hmw can be used. This database uses an activity coefficient scheme advanced by Harvie-Moller-Weare (Harvie et al., 1984). It contains thermodynamic data for a large number of evaporite minerals. Unfortunately, the list of elements included in this high ionic strength database is much less extensive than the com database and doesn't includes data for temperatures greater than $25^{\circ} \mathrm{C}$. A comparison between these two databases is summarized below: 


\begin{tabular}{|l|l|l|l|}
\hline Database & Temperature limits & Ionic strength limits & $\begin{array}{l}\text { Elements } \\
\text { considered }\end{array}$ \\
\hline $\mathrm{com} / \mathrm{cmp}$ & $0-300^{\circ} \mathrm{C}$ & $\begin{array}{l}\text { Dilute solutions } \\
(<\sim 1 \text { molal })\end{array}$ & $\begin{array}{l}\text { Broad range of } \\
\text { elements and } \\
\text { species }\end{array}$ \\
\hline $\mathrm{hmw}$ & $25^{\circ} \mathrm{C}$ only & $\begin{array}{l}\text { Dilute solutions or } \\
\text { concentrated brines }\end{array}$ & No Si, N, F \\
\hline
\end{tabular}

Thus, we face a compromise in any calculation. When we use the hmw database to model the evaporation experiments, we can no longer account for the elements $\mathrm{Si}, \mathrm{F}$ or $\mathrm{N}$, nor can we account for temperatures above $25^{\circ} \mathrm{C}$. Below about 1 molal ionic strength, the com database should provide reasonably accurate thermodynamic calculations. Beyond that we are limited to the hmw database, with the understanding that we are pushing the limits of this modeling approach and should expect model results to be approximations at best. See Wolery (1992) for further discussion on the various thermodynamic databases available for use with EQ3/6. Kinetic effects may also be important and this modeling approach only includes kinetics indirectly through the selective suppression of mineral phases considered.

All these caveats not withstanding, as we will show below, the correspondence between our modeling simulations and experimental data is (perhaps) surprisingly good.

\section{Modeling synthetic J13 water experiments}

We performed calculations of our synthetic J13 water using both EQ3/6 (Wolery, 1998) and REACT (Bethke, 1998). The exact same thermodynamic data is used with each code (i.e., data0.com.R2 and thermo.com.V8.R6, for EQ3/6 and REACT respectively, which only differ in their formatting). We use EQ3/6 for the speciation/solubility calculations (e.g., to detcrminc charge balance in the sampled solutions in which $\mathrm{pH}$ is mcaningfully measured as a check of analytical accuracy) and REACT, with both the com and hmw thermodynamic databases, for simulating the evaporative evolution.

In all our experiments, the evaporation occurs in the absence of boiling, so the process can be modeled as starting with $1 \mathrm{~kg}$ of water and "titrating out" water at any given temperature (using the com database) and at $25^{\circ} \mathrm{C}$ (using the hmw database). $\mathrm{CO}_{2}$ fugacity was held constant. Note that all of the caveats previously mentioned above concerning model and database limitations apply. Here, we only present models of the evaporation of J13 water alone (evapl and evap4). We present speciation/solubility calculations for experiments with and without tuff present (evap1 and evap2).

\section{Calculation of ionic strength for concentrated solutions}

The results of ionic strength calculations we performed using EQ3/6 indicate that for the $\sim 1000 \mathrm{x}$ concentrated solutions, the ionic strengths were above 1.5 molal and for the rewet solutions, the ionic strengths were $0.6-0.7$ molal. This calculation is strictly a 
speciation/solubility calculation with no reaction progress, (i.e., no evaporation). The calculated ionic strengths support our comments earlier regarding the validity of the $\mathrm{pH}$ measurement in the rewet samples, and the invalidity of a $\mathrm{pH}$ measurement in the $1000 \mathrm{x}$ samples.

\section{Modeling evaporation of synthetic J13 water alone using com database}

The starting point in the calculations is the initial composition of the synthetic J13 water as given in Table 3 . We then use $\mathrm{Na}$ to balance the solution electrically by adjusting its concentration. We set this step to occur at $25^{\circ} \mathrm{C}$ without precipitating any minerals that might be already supersaturated. We then "pickup" the electrically neutral solution composition (and jump the temperature to $85^{\circ} \mathrm{C}$ in the case of a run using the com database) and start removing $\mathrm{H}_{2} \mathrm{O}$ from the system, equilibrating the fluid after each iterative water removal. Precipitation is allowed to occur at all steps following the initial charge balance.

Note that in the simulation we have chosen to suppress several mineral species that, although thermodynamically favored, are known to be slow in precipitating, and unlikely to form in this system at these temperatures. For example, we suppress all the silica polymorphs more thermodynamically stable than amorphous silica. We also suppress a number of aluminosilicate phases that would not precipitate under these condition (e.g., diopside, forsterite).

In Fig. 4, we display the results from calculations made to simulate evaporation of synthetic $\mathrm{J} 13$ water at $85^{\circ} \mathrm{C}$ using the com database along with data from our experiments as given in Tables 3,5 and 6. Note that the solution compositions are given in elemental concentration (to simplify the presentation by avoiding dealing with aqueous speciation). The $\mathrm{x}$-axis is the concentration factor on a log scale for ease in direct comparison to the experimental data that are plotted on the same figure. Given that the thermodynamic data are only reliable to a concentration factor of 200-300 for our synthetic J13 water and the last measurement occurs at approximately a 1000-fold concentration, we only plot the fluid-phase simulation results out to a concentration factor of $1000 \mathrm{x}$.

In Fig. 5, we plot the minerals that are calculated to be in the equilibrium mineral assemblage as the solution composition evolves during evaporation. Note that we have carried out the simulation to much higher concentration factors than plotted in the aqueous-phase element concentration plots. We did this because few minerals precipitate until after a concentration factor considerably higher than $1000 x$. Furthermore, this allows us to compare the predicted mineral assemblage at nearly complete evaporation to that actually determined by XRD after complete evaporation. As a comparison of Figure 5 with Table 7 shows, there is a fair degree of correspondence. Minerals predicted to form, but not observed in our experiment may be present in minor amounts possibly not detectable using XRD. The minerals predicted to form, but not observed, include: huntite $\left(\mathrm{CaMg}_{3}\left(\mathrm{CO}_{3}\right)_{4}\right)$, fluorite $\left(\mathrm{CaF}_{2}\right)$, thenardite $\left(\mathrm{Na}_{2} \mathrm{SO}_{4}\right)$ and arcanite $\left(\mathrm{K}_{2} \mathrm{SO}_{4}\right)$. 
The solution element concentrations predicted by the model that differ the most from measurement are $\mathrm{Ca}, \mathrm{Mg}$, and $\mathrm{Si}$. $\mathrm{Ca}$ and $\mathrm{Mg}$ are present in carbonate minerals in both the model and our experiment. Si as amorphous silica was observed in our experiment at $1000 \mathrm{x}$ concentration, but not predicted by the model until the solution becomes much more concentrated. The measured concentration of these elements is generally higher than that predicted in the simulation. This suggests that the filter pore size $(0.45 \mu \mathrm{m})$ may have been too large and a small amount of suspended mineral may have been included with the aqueous sample submitted for analysis. The predicted solution elemental compositions are relatively close to the measured values for the other elements.

\section{Modeling evaporation of synthetic J13 water alone using hmw database}

We now present the results of model simulation of evaporation of synthetic J13 water using the hmw thermodynamic database. Note that the initial composition of our synthetic J13 water needed to be modified to contain only elements present in the hmw database. This means that the elements F, N and Si must be dropped from the model. As a result, the charge balance using $\mathrm{Na}$ that occurs during the first step of the calculation must also accommodate the loss of these three elements from the chemical system. In addition, the hmw database has no provision for temperatures other than $25^{\circ} \mathrm{C}$, so the simulation models evaporation at this temperature; there is no temperature jump to $85^{\circ} \mathrm{C}$. On the positive side, the hmw database was specifically designed to model solution equilibrated with evaporite minerals, so the minerals contained in the database are more appropriate and the activity coefficient extrapolations are accurate to very high ionic strength.

In Fig. 6, we display the results from calculations made using the hmw database. The plots are completely analogous to those presented earlier for the com database (Fig. 4). Note that the experimental results are those from the $85^{\circ} \mathrm{C}$ evaporation of synthetic $\mathrm{J} 13$ water, whereas the simulated evaporation in this case occurred at $25^{\circ} \mathrm{C}$.

In Fig. 7 we plot the minerals that are calculated to be in the equilibrium mineral assemblage as the solution composition evolves during cvaporation. These can be compared to the results of XRD analyses given in Table 7 . The minerals predicted to form that were not observed in our experiments include: nesquehonite $\left(\mathrm{Mg}(\mathrm{HCO} 3)(\mathrm{OH}): 2 \mathrm{H}_{2} \mathrm{O}\right)$, gaylussite $\left(\mathrm{Na}_{2} \mathrm{Ca}\left(\mathrm{CO}_{3}\right)_{2}: 5 \mathrm{H}_{2} \mathrm{O}\right)$, pirssonite $\left(\mathrm{Na}_{2} \mathrm{Ca}\left(\mathrm{CO}_{3}\right)_{2}: 2 \mathrm{H}_{2} \mathrm{O}\right)$, aphthitalite $\left((\mathrm{K}, \mathrm{Na})_{3} \mathrm{Na}\left(\mathrm{SO}_{4}\right)_{2}\right)$ and burkeite $\left(\mathrm{Na}_{6}\left(\mathrm{CO}_{3}\right)\left(\mathrm{SO}_{4}\right)_{2}\right)$. Naturally, the simulation fails to account for the presence of fluoride, nitrate or silica minerals in the assemblage, because these elements are not present in the model. Note that in this simulation we have suppressed only two mineral species: dolomite and magnesite. All the other minerals present in the hmw thermo database are active in the simulation.

Because the suite of minerals in the hmw database differs from that in the com database, not only are the specific minerals predicted to form slightly different, the predicted solution composition must necessarily be different. The most notable difference between the hmw and com results is in the predicted $\mathrm{Mg}$ concentration. The hmw simulation 
predicts that $\mathrm{Mg}$ solution composition is controlled by equilibrium with nesquehonite, $\mathrm{a}$ mixed bicarbonate-hydroxide salt, with an aqueous solubility considerably higher than the pure carbonate mineral (huntite) that served as a $\mathrm{Mg}$ sink in the com simulation. The solution elemental $\mathrm{Mg}$ concentration reflects this difference. Another notable difference is in the predicted $\mathrm{pH}$ of the solutions. The hmw simulation underpredicts the $\mathrm{pH}$ more than the com simulation due to the formation of the hydroxide mineral, nesquehonite.

\section{Application to near-field water at Yucca Mountain}

The results presented thus far for our synthetic $\mathrm{J} 13$ water have shown that within the limits of our modeling capability, model results are in a surprisingly good agreement with experimental results. We now use models to calculate the results that one might expect if the water composition were modified to represent other possible near-field waters at Yucca Mountain. We consider three water compositions. The first is actual J13 well water, based on the solution composition provided in Table 1. In this instance, just like with the synthetic J13 water, we assume that the solution is maintained constantly in equilibrium with respect to the $\mathrm{CO}_{2}$ in the atmosphere.

Since at some locations, it is reasonable to expect that $\mathrm{CO}_{2}$ levels may vary during the lifetime of a nuclear waste repository, we also consider cases in which $\mathrm{CO}_{2}$ levels are higher and lower than atmospheric values. In the second model, we use the actual J13 well water composition, but we assume that the solution is equilibrated with a gas phase containing a $\mathrm{CO}_{2}$ levels 100 times greater than that of the atmosphere. In the third model, we assume that the solution is equilibrated with a gas phase containing a $\mathrm{CO}_{2}$ levels 100 times less than that of the atmosphere. For each model, we make separate calculations using the two thermodynamic databases as done in the previous sections: com and hmw.

In Fig. 8, we present the results of equilibrium thermodynamic calculations based on the com database in which the waters are evaporatively concentrated up to 1000 -fold. We only present those results in which the model results are significantly different from those of synthetic J13 water, already presented in this report (Figs. 4-7). To make the comparison more direct, we include in the same plots results for all four water compositions: synthetic J13 water, J13 well water, J13 well water in equilibrium with high levels of $\mathrm{CO}_{2}$, and $\mathrm{J} 13$ well water in equilibrium with low levels of $\mathrm{CO}_{2}$.

In this figure, several points can be made. First, the differences between synthetic J13 water and actual J13 well water are very slight with the exception of Si which differs due to the different initial concentrations only. It is clear that the other differences seen in Fig. 8 are mainly those directly attributable to the impact of $\mathrm{CO}_{2}$ (i.e., pH). The high $\mathrm{CO}_{2}$ $\mathrm{J} 13$ solution has a $\mathrm{pH}$ nearly two $\mathrm{pH}$ units lower than either synthetic $\mathrm{J} 13$ water or actual $\mathrm{J} 13$ well water and the low $\mathrm{CO}_{2} \mathrm{~J} 13$ solution has a much higher $\mathrm{pH}$. The Si differs simply as a function of the solubility of the silica phases (i.e., these phases are significantly more soluble at $\mathrm{pH}>9.9)$. At lower concentration factors $(<100 \mathrm{x})$ the high $\mathrm{CO}_{2}$ case shows that both $\mathrm{Ca}$ and $\mathrm{Mg}$ initially accumulate in the fluid until eventually the carbonate phases become supersaturated. After this point in the evaporative 
concentration, the $\mathrm{Ca}$ and $\mathrm{Mg}$ concentrations decrease markedly and approach those of the lower $\mathrm{CO}_{2}$ waters.

In Fig. 9, we present results from a similar set of simulations, this time using the hmw thermodynamic database. As before, we present only results for the elements that differ significantly from those presented earlier for synthetic J13 water. Of course, in this case there is no $\mathrm{Si}$ in the simulation owing to the lack of Si thermodynamic data in the hmw database. Once again, the differences between the results obtained for synthetic J13 water and actual $\mathrm{J} 13$ well water are very slight. The high $\mathrm{CO}_{2} \mathrm{~J} 13$ water simulation again displays a significantly lower $\mathrm{pH}$ and this difference manifests itself in the solution composition for $\mathrm{C}, \mathrm{Ca}$ and $\mathrm{Mg}$ primarily. The total $\mathrm{C}$ in solution is lower because the solubility of $\mathrm{CO}_{2}$ decreases with decreased $\mathrm{pH}$. The $\mathrm{Ca}$ accumulation in the fluid is again explained directly by the increase in carbonate mineral solubility with lower $\mathrm{pH}$. The increased $\mathrm{Mg}$ concentration beyond $100 \mathrm{x}$ concentration factor (vs. the lower $\mathrm{CO}_{2}$ simulations) is also attributable to lower $\mathrm{pH}$.

For $\mathrm{J} 13$ water in equilibrium with atmospheric $\mathrm{CO}_{2}$ levels, the model (with com data base) predicts about $0.1 \mathrm{~cm}^{3}$ of mineral precipitates form per $1 \mathrm{~kg}$ of solution. 


\section{References}

Apps, J.A. 1997. "Hydrogeochemical Analysis." The Site-Scale Unsaturated Zone Model of Yucca Mountain, Nevada, for the Viability Assessment (Chapler 14). Las Vegas, Nevada: Civilian Radioactive Waste Management System, Management and Operating Contractor. MOL.19971014.0232. (Section 14.5.3)

Bates, R. G. 1964. Determination of $p H$ : theory and practice, John Wiley and Sons, New York, 435 pages. (p. 31).

Bethke, C.M. 1998. The Geochemist's Workbench ${ }^{\mathrm{TM}}$, Version32.0. A User's Guide to Rxn, Act2, Tact, React, and Gtplot. Champaign, Illinois: Hydrology Program, University of Illinois.

Bish, D.L., Caporuscio, F.A., Copp, J.F., Crowe, B.M., Purson, J.D., Smyth, J.R., and Warren, R.G. 1981. LA-8840-MS. Los Alamos, New Mexico: Los Alamos National Laboratory.

CRWMS M\&O. 1998. Total System Performance Assessment-Viability Assessment Analyses, Technical Basis Document: Chapter 4: Near-Field Geochemical Environment. B0000000001717-4301-00004 REV 01. Las Vegas, Nevada: Civilian Radioactive Waste Management System, Management and Operating Contractor, TRW Environmental Safety Systems, Inc. MOL.19981008.0004.

Harrar, J., Carley, J.F., Isherwood, W.F., and Raber, E. 1990. Report of the Committee to Review the Use of $J 13$ Well Water in Nevada Nuclear Waste Storage Investigations. UCRLID-21867. Livermore, California: Lawrence Livermore National Laboratory. LL980711104242.054. NNA.910131.0274. (Table 4.1).

Harvie, C.E., Moller, N., and Weare, J.H. 1984. "The prediction of mineral solubilities in natural waters: the $\mathrm{Na}-\mathrm{K}-\mathrm{Mg}-\mathrm{Ca}-\mathrm{H}-\mathrm{Cl}-\mathrm{SO}_{4}-\mathrm{OH}-\mathrm{HCO}_{3}-\mathrm{CO}_{3}-\mathrm{CO}_{2}-\mathrm{H}_{2} \mathrm{O}$ system to high ionic strengths at $25^{\circ} \mathrm{C}$." Geochim. Cosmochim. Acta 48(4):723-751.

Knauss, K.G., Wolery, T.J., and Jackson, K.J. 1991. "Reply to comment by R.E. Mesmer on, A new approach to measuring pH in brines and other concentrated electrolytes." Geochim. Cosmochim. Acta 55:1177-1179.

Knauss, K.G., Wolery, T.J., and Jackson, K.J. 1990. "A new approach to measuring pH in brines and other concentrated electrolytes." Geochim. Cosmochim. Acta 54:1519-1523.

McCright, R.D. 1998. Engineered Materials Characterization Report, Volume 3, Revision 1.1: Corrosion Data and Modeling Update for Viability Assessment. Milestone report for the CRWMS Management and Operating Contractor, U.S. Department of Energy. UCRL-ID-119564 Vol. 3 Rev. 1.1. WP20AM3. Livermore, California: Lawrence Livermore National Laboratory.

Sonnenthal, E., Spycher, N., and Simmons, A. 1998. Thermo-Hydro-Chemical Predictive Analysis for the Drift-Scale Heat Test. Level 4 Milestone. SPY289M4, V. 1. Berkeley, California: Lawrence Berkeley National Laboratory. MOL.19981130.0132.

Wolery, T. J. 1998. EQ3/6, a software package for geochemical modeling Version $7.2 b$ (UCRLCODE-99015).

Wolery, T.J. 1992. EQ3NR, A Computer Program For Geochemical Aqueous SpeciationSolubility Calculations: Theoretical Manual, User's Guide, and Related Documentation. UCRL-MA-110662. Livermore, California: Lawrence Livermore National Laboratory. NNA.19921218.0010. Version 7.0. Chapter 1. 


\section{Tables}

Table 1. Major ion concentrations reported for $\mathrm{J} 13$ well water

Table 2. Chemistry of average synthetic J13 water use in the present study

Table 3. Water chemistry from experiment with synthetic J13 water alone

Table 4. Water chemistry from experiment with synthetic $J 13$ water with tuff

Table 5. $\mathrm{pH}$ evolution from short-term experiment with syntheticJ13 water alone

Table 6. Water chemistry from short-term experiment with synthetic J13 water alone

Table 7. Mineralogical results from experiment with synthetic J13 water alone

Table 8. Mineralogical results from experiment with synthetic J13 water with tuff

Table 9. Mass of minerals formed in experiments with synthetic J13 water 
Table 1. Major ion concentrations reported for J13 well water

\begin{tabular}{ll}
\hline Ions & $\mathrm{mg} / \mathrm{L}^{*}$ \\
$\mathrm{Ca}^{++}$ & $13.0 \pm 0.99$ \\
$\mathrm{Cl}^{-}$ & $7.14 \pm 0.61$ \\
$\mathrm{~F}^{-}$ & $2.18 \pm 0.29$ \\
$\mathrm{HCO}_{3}^{-* *}$ & $128.9 \pm 8.6$ \\
$\mathrm{~K}^{+}$ & $5.04 \pm 0.61$ \\
$\mathrm{Mg}^{+}$ & $2.01 \pm 0.21$ \\
$\mathrm{NO}_{3}^{-}$ & $8.78 \pm 1.03$ \\
$\mathrm{Na}^{+}$ & $45.8 \pm 2.29$ \\
$\mathrm{SO}_{4}^{-}$ & $18.4 \pm 1.03$ \\
$\left.\mathrm{Si}^{-} \mathrm{aq}\right)^{* * *}$ & $28.5 \pm 1.85$ \\
& \\
$\mathrm{pH}^{* * * *}$ & $7.41 \pm 0.44$ \\
\hline
\end{tabular}

* Data are from Harrar et al. (1990), Table 4.1. These values represent the mean concentration values of water collected from this well over the course of about 20 years of sampling. These values represent the mean value of 15-20 analyses, each of which is the mean of replicate sampling in many cases.

** Alkalinity is expressed as $\mathrm{mg} / \mathrm{L} \mathrm{HCO}_{3}^{-}$.

*** The conversion from Si to $\mathrm{SiO}_{2}$ is: $1 \mathrm{mg} / \mathrm{L} \mathrm{Si}$ is $2.14 \mathrm{mg} / \mathrm{L} \mathrm{SiO}_{2}$.

**** The range reported is $6.8-8.3$. This value represent the mean $\mathrm{pH}$ values of water collected from this well over the course of about 20 years of sampling. As Apps (1997) has pointed out, the subsurface (in situ) $\mathrm{pH}$ of $\mathrm{J} 13$ well water is problematic. 
Table 2. Chemistry of average synthetic J13 water used in the present study

\begin{tabular}{ll}
\hline Ions & $\mathrm{mg} / \mathrm{kg}^{*}$ \\
$\mathrm{Ca}^{++}$ & $5.8 \pm 0.6$ \\
$\mathrm{Cl}^{-}$ & $7.2 \pm 0.3$ \\
$\mathrm{~F}^{-}$ & $2.3 \pm 0.1$ \\
$\mathrm{HCO}_{3}^{-}$ & $105 . \pm 2$. \\
$\mathrm{K}^{+}$ & $5.2 \pm 0.2$ \\
$\mathrm{Mg}^{++}$ & $2.1 \pm 0.1$ \\
$\mathrm{NO}_{3}^{-}$ & $7.9 \pm 0.1$ \\
$\mathrm{Na}^{+}$ & $45.2 \pm 0.8$ \\
$\mathrm{SO}_{4}^{--}$ & $18.5 \pm 0.5$ \\
$\mathrm{SiO}_{2}(\mathrm{aq})$ & $10.4 \pm 0.9$ \\
& \\
& $\mathrm{pH}$ \\
\hline
\end{tabular}

* The density of water at $25^{\circ} \mathrm{C}$ is 1.013 , therefore $\mathrm{mg} / \mathrm{kg} \cong \mathrm{mg} / \mathrm{L}$. Note that these values are the average of three batch solutions for the evap1 experiment, and single batch solutions for the evap2 and evap4 experiments. 
Table 3. Water chemistry from experiment with synthetic J13 water alone

\begin{tabular}{|c|c|c|c|c|c|}
\hline & $\begin{array}{c}\text { synthetic J13 } \\
\text { (evap1) }\end{array}$ & $\begin{array}{l}\text { Concentration } \\
\text { Factor: } 956 \mathrm{x}^{*}\end{array}$ & $\begin{array}{l}\text { Concentration } \\
\text { ratio }\end{array}$ & rewet** & $\begin{array}{l}\text { Concentration } \\
\text { ratio }\end{array}$ \\
\hline \multicolumn{6}{|l|}{ ions $(\mathrm{mg} / \mathrm{kg}$ ) } \\
\hline $\mathrm{Ca}^{+}$ & 6.4 & 29.86 & 4.7 & 3.48 & .54 \\
\hline $\mathrm{Cl}^{-}$ & 6.9 & 4,835 & 701 & 1,773 & 257 \\
\hline $\mathrm{F}^{-}$ & 2.2 & 1,550 & 705 & 530 & 241 \\
\hline $\mathrm{HCO}_{3}^{-}$ & 108 & 24,878 & 231 & 9,539 & 88.3 \\
\hline $\mathrm{K}+$ & 5.3 & 4,792 & 904 & 1,364 & 257 \\
\hline $\mathrm{Mg}^{++}$ & 2.2 & 0.14 & .06 & 0.09 & .04 \\
\hline $\mathrm{NO}_{3}^{-}$ & 8.0 & 5,532 & 694 & 2,016 & 252 \\
\hline $\mathrm{Na}^{+}$ & 46. & 44,082 & 958 & 12,512 & 272 \\
\hline $\mathrm{SO}_{4}^{-}$ & 18.1 & 12,926 & 714 & 4,631 & 256 \\
\hline $\mathrm{SiO}_{2}(\mathrm{aq})$ & 11.3 & 18,008 & $1,594 * * *$ & 3,606 & 319 \\
\hline $\mathrm{pH}$ & 7.84 & & & 10.59 & \\
\hline
\end{tabular}

* $30 \mathrm{~L}$ of synthetic J13 water were evaporated down to $30 \mathrm{ml}$ of solution, resulting in an evaporative concentration factor of approximately $1000 \mathrm{x}$.

** After the solution was then evaporated completely to dryness, the salts were then rewet with $200 \mathrm{~mL}$ of deionized water, evaporatively concentrated down to $100 \mathrm{~mL}$.

*** The apparent concentration ratio for $\mathrm{SiO}_{2}$ is higher than either that estimated by mass measurement or by the concentration of the other cations or the anions, and most likely represents an analytic difficulty due to the relatively high ionic strength in the analytical solution. 
Table 4. Water chemistry from experiment with synthetic J13 water with tuff

\begin{tabular}{|c|c|c|c|c|c|}
\hline & $\begin{array}{l}\text { synthetic J13 } \\
\text { (evap2) }\end{array}$ & $\begin{array}{l}\text { Concentratio } \\
\text { Factor: } \\
1114 x^{*}\end{array}$ & $\begin{array}{l}\text { Concentration } \\
\text { ratio }\end{array}$ & rewet** & $\begin{array}{l}\text { Concentration } \\
\text { ratio }\end{array}$ \\
\hline \multicolumn{6}{|l|}{ ions $(\mathrm{mg} / \mathrm{kg})$} \\
\hline $\mathrm{Ca}^{++}$ & 5.6 & 6.9 & 1.2 & 3 & .5 \\
\hline $\mathrm{Cl}^{-}$ & 7.2 & 6123 & 850 & 2,349 & 326 \\
\hline $\mathrm{F}^{-}$ & 2.2 & 1,522 & 691 & 605 & 275 \\
\hline $\mathrm{HCO}_{3}^{-}$ & 104. & 31,434 & 303 & 13,434 & 129 \\
\hline $\mathrm{K}+$ & 5.3 & 3,716 & 702 & 1,553 & 292 \\
\hline $\mathrm{Mg}^{++}$ & 2.1 & $<0.28$ & - & $<0.08$ & -- \\
\hline $\mathrm{NO}_{3}^{-}$ & 7.8 & 6,729 & 863 & 2,598 & 333 \\
\hline $\mathrm{Na}^{+}$ & 44.3 & 37,713 & 851 & 14,520 & 327 \\
\hline $\mathrm{SO}_{4}^{--}$ & 18.3 & 15,711 & 858 & 6,138 & 336 \\
\hline $\mathrm{SiO}_{2}(\mathrm{aq})$ & 9.4 & 7,118 & 758 & 2,691 & 287 \\
\hline $\mathrm{pH}$ & 8.03 & & & 9.99 & \\
\hline
\end{tabular}

* $\quad 30 \mathrm{~L}$ of synthetic $\mathrm{J} 13$ water were evaporated down to $30 \mathrm{ml}$ of solution, resulting in an evaporative concentration factor of approximately $1000 \mathrm{x}$.

** After the solution was then evaporated completely to dryness, the salts were then rewet with $200 \mathrm{~mL}$ of deionized water, evaporatively concentrated down to $100 \mathrm{~mL}$. 
Table 5. $\mathrm{pH}$ evolution from short-term experiment with synthetic J13 water alone (evap4)

\begin{tabular}{cc} 
Concentration & $\mathrm{pH}$ \\
Factor* & \\
1.00 & 8.46 \\
1.00 & 8.65 \\
1.05 & 9.04 \\
1.29 & 9.43 \\
1.60 & 9.58 \\
2.41 & 9.67 \\
6.08 & 9.67 \\
6.37 & 9.77 \\
7.59 & 9.79 \\
11.6 & 9.95 \\
12.6 & 10.00 \\
15.3 & 10.03 \\
20.9 & 10.08 \\
25.2 & 10.09 \\
34.4 & 10.12 \\
52.1 & 10.18 \\
104. & 10.18 \\
157. & 10.18 \\
\hline
\end{tabular}

* This table represents the combined results of a four-day run with $\mathrm{pH}$ measured approximately every other hour and another from a very short run lasting only three hours that was measured approximately every 20 minutes or less. 
Table 6. Water chemistry from short-term experiment with synthetic J13 water alone

\begin{tabular}{|c|c|c|c|}
\hline & $\begin{array}{l}\text { synthetic J13 } \\
\text { (evap4) }\end{array}$ & $157 \mathrm{x}$ & $\begin{array}{c}\text { Concentration } \\
\text { Factor }\end{array}$ \\
\hline \multicolumn{4}{|l|}{ ions $(\mathrm{mg} / \mathrm{kg})$} \\
\hline $\mathrm{Ca}^{++}$ & 5.3 & 1.2 & .01 \\
\hline $\mathrm{Cl}^{-}$ & 7.5 & 849 & 113 \\
\hline $\mathrm{F}^{-}$ & 2.4 & 247 & 103 \\
\hline $\mathrm{HCO}_{3}^{-}$ & 103. & 4,295 & 42 \\
\hline $\mathrm{K}+$ & 4.9 & 560 & 114 \\
\hline $\mathrm{Mg}^{+1}$ & 2.1 & 0.05 & .57 \\
\hline $\mathrm{NO}_{3}^{-}$ & 8.0 & 1,050 & 131 \\
\hline $\mathrm{Na}^{+}$ & 45.4 & 5,298 & 117 \\
\hline $\mathrm{SO}_{4}^{--}$ & 19 & 2,162 & 114 \\
\hline $\mathrm{SiO}_{2}(\mathrm{aq})$ & 10 & 999 & 100 \\
\hline $\mathrm{pH}$ & 8.33 & 10.18 & \\
\hline
\end{tabular}


Table 7. Mineralogical results from experiment with synthetic J13 water alone

evap1 - 956x

$\mathrm{SiO}_{2}$ (amorphous)

aragonite $\left(\mathrm{CaCO}_{3}\right)$

calcite $\left(\mathrm{CaCO}_{3}\right)$ evap1 - complete evaporation

$\mathrm{SiO}_{2}$ (amorphous)

aragonite $\left(\mathrm{CaCO}_{3}\right)$

calcite $\left(\mathrm{CaCO}_{3}\right)$

halite $(\mathrm{NaCl})$

niter $\left(\mathrm{KNO}_{3}\right)$

thermonatrite $\left(\mathrm{Na}_{2} \mathrm{CO}_{3}: \mathrm{H}_{2} \mathrm{O}\right)$

gypsum? $\left(\mathrm{CaSO}_{4}: 2 \mathrm{H}_{2} \mathrm{O}\right)$

anhydrite? $\left(\mathrm{CaSO}_{4}\right)$

hectorite? $\left(\mathrm{Na}_{0.33} \mathrm{Mg}_{3} \mathrm{Si}_{4} \mathrm{O}_{10}(\mathrm{~F}, \mathrm{OH})_{2}\right)$

Table 8. Mineralogical results from experiment with synthetic J13 water with tuff

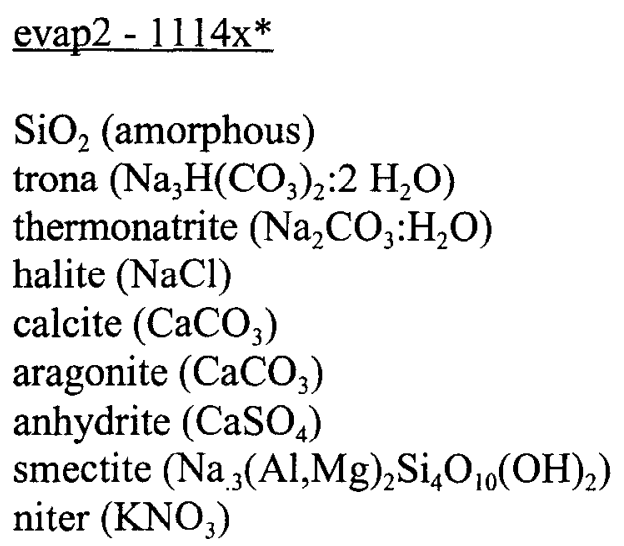

evap2 - complete evaporation*

$\mathrm{SiO}_{2}$ (amorphous)

trona $\left(\mathrm{Na}_{3} \mathrm{H}\left(\mathrm{CO}_{3}\right)_{2}: 2 \mathrm{H}_{2} \mathrm{O}\right)$

thermonatrite $\left(\mathrm{Na}_{2} \mathrm{CO}_{3}: \mathrm{H}_{2} \mathrm{O}\right)$

halite $(\mathrm{NaCl})$

calcite $\left(\mathrm{CaCO}_{3}\right)$

aragonite $\left(\mathrm{CaCO}_{3}\right)$

anhydrite $\left(\mathrm{CaSO}_{4}\right)$

smectite $\left(\mathrm{Na}_{3}(\mathrm{Al}, \mathrm{Mg})_{2} \mathrm{Si}_{4} \mathrm{O}_{10}(\mathrm{OH})_{2}\right)$

* Only the minerals produced by evaporation and not present in the starting tuff are reported here. The tuff used is made up of: crystobalite (alpha), Kfeldspar, albite, anorthite, quartz (Bish et al., 1981). 
Table 9. Mass of minerals formed in experiments with synthetic J13 water $\begin{array}{ll}\text { synthetic J13 water alone (evap1) } & 5.636 \mathrm{~g} \\ \text { synthetic J13 water with tuff (evap2) } & 6.468 \mathrm{~g}\end{array}$ synthetic J13 water with tuff (evap2) $\quad 6.468 \mathrm{~g}$ 


\section{Figures}

Fig. 1. Relative distribution of ions for synthetic J13 water evaporation experiments

Fig. 2. Concentration of chemical species in synthetic J13 evaporation experiments

Fig. 3. $\mathrm{pH}$ vs. concentration factor for short-term evaporation experiment with $\mathrm{J} 13$ water alone

Fig. 4. Comparison of modeling results and experimental data from the evaporation experiments with synthetic J13 water alone, using com database

Fig. 5. Predicted mineralogical evolution during evaporation of synthetic J13 water alone, using com database

Fig. 6. Comparison of modeling results and experimental data from the evaporation experiments with synthetic J13 water alone, using hmw database

Fig. 7. Predicted mineralogical evolution during evaporation of synthetic J13 water alone, using hmw database

Fig. 8. Predicted evolution of fluid chemistry during evaporation of synthetic J13, actual $\mathrm{J} 13$ and $\mathrm{J} 13$ with high and low $\mathrm{CO} 2$ water compositions (com database)

Fig. 9. Predicted evolution of fluid chemistry during evaporation of synthetic J13, actual $\mathrm{J} 13$ and $\mathrm{J} 13$ with high and low $\mathrm{CO} 2$ water compositions (hmw database) 


\section{CATIONS}
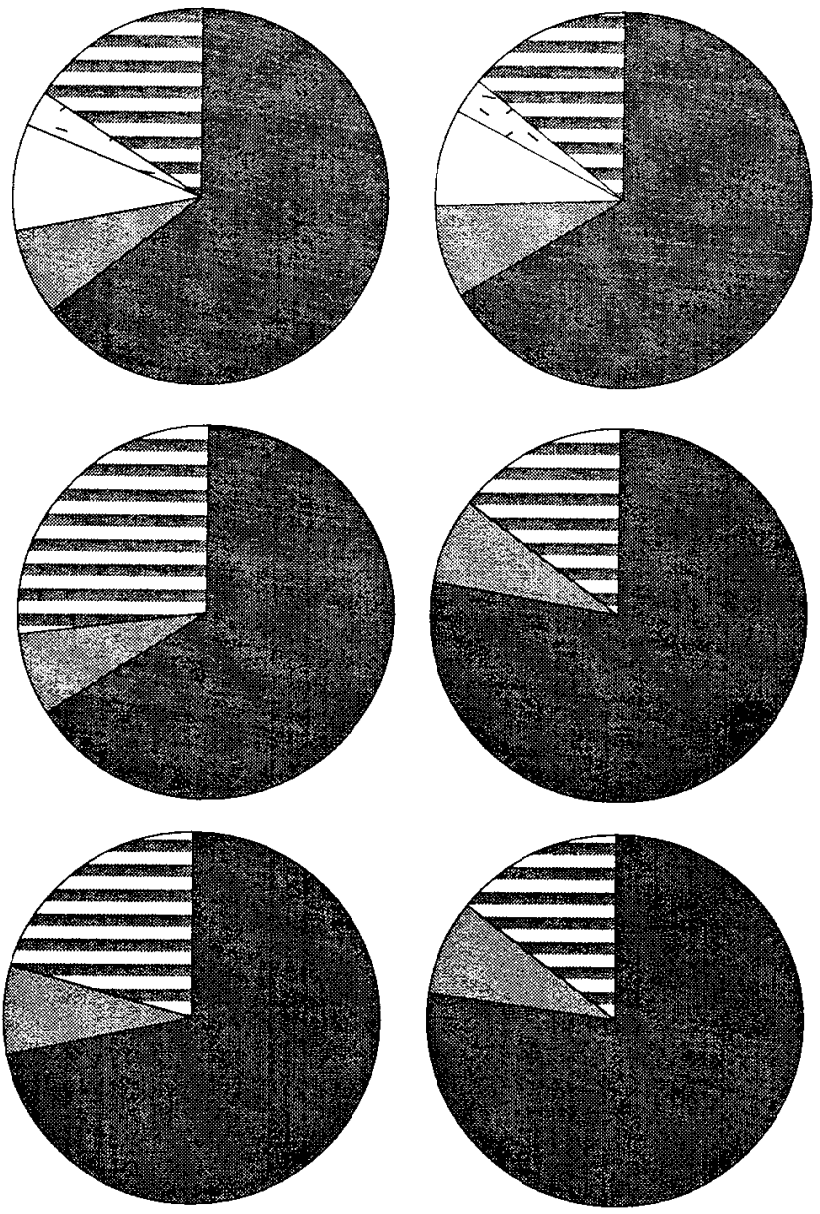

syn J13

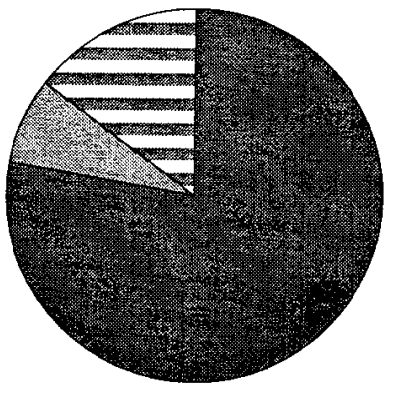

$\sim 1000 \mathrm{x}$

$(85 C)$

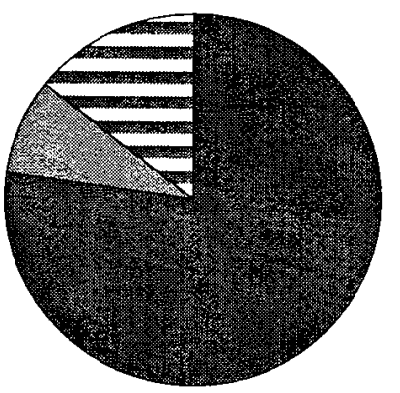

rewet

(75C)

no tuff with crushed tuff

Na+ $\square \mathrm{Ca}++$

㬝 $\mathrm{K}+$

$\because \mathrm{Mg}++$

$\stackrel{+}{+}$
ANIONS
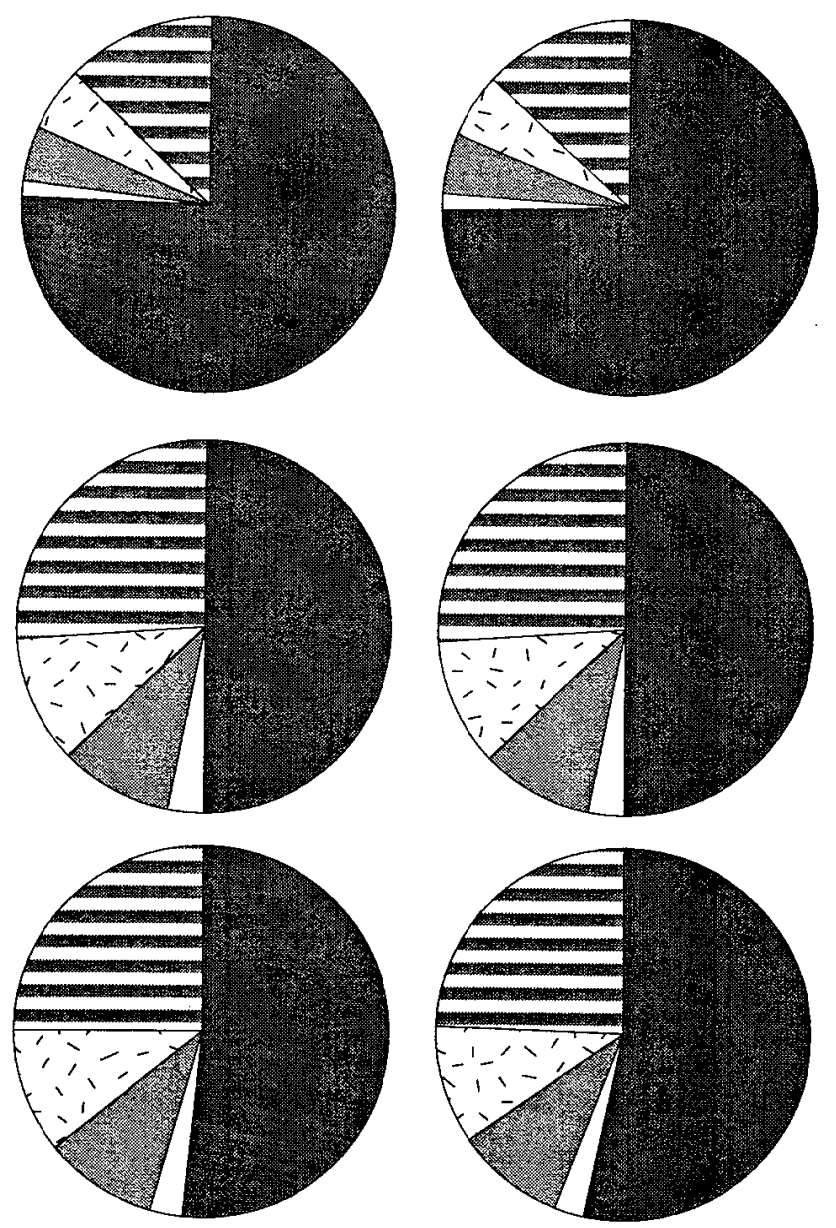

rewet

(75C)

(85C)

\section{no tuff with crushed tuff}

$\sim 1000 \mathrm{x}$

ECO3- $\square$ NO3-

$\square$ F- SO4-

Cl-

Fig. 1. Relative distribution of ions for synthetic J13 water evaporation experiments. 


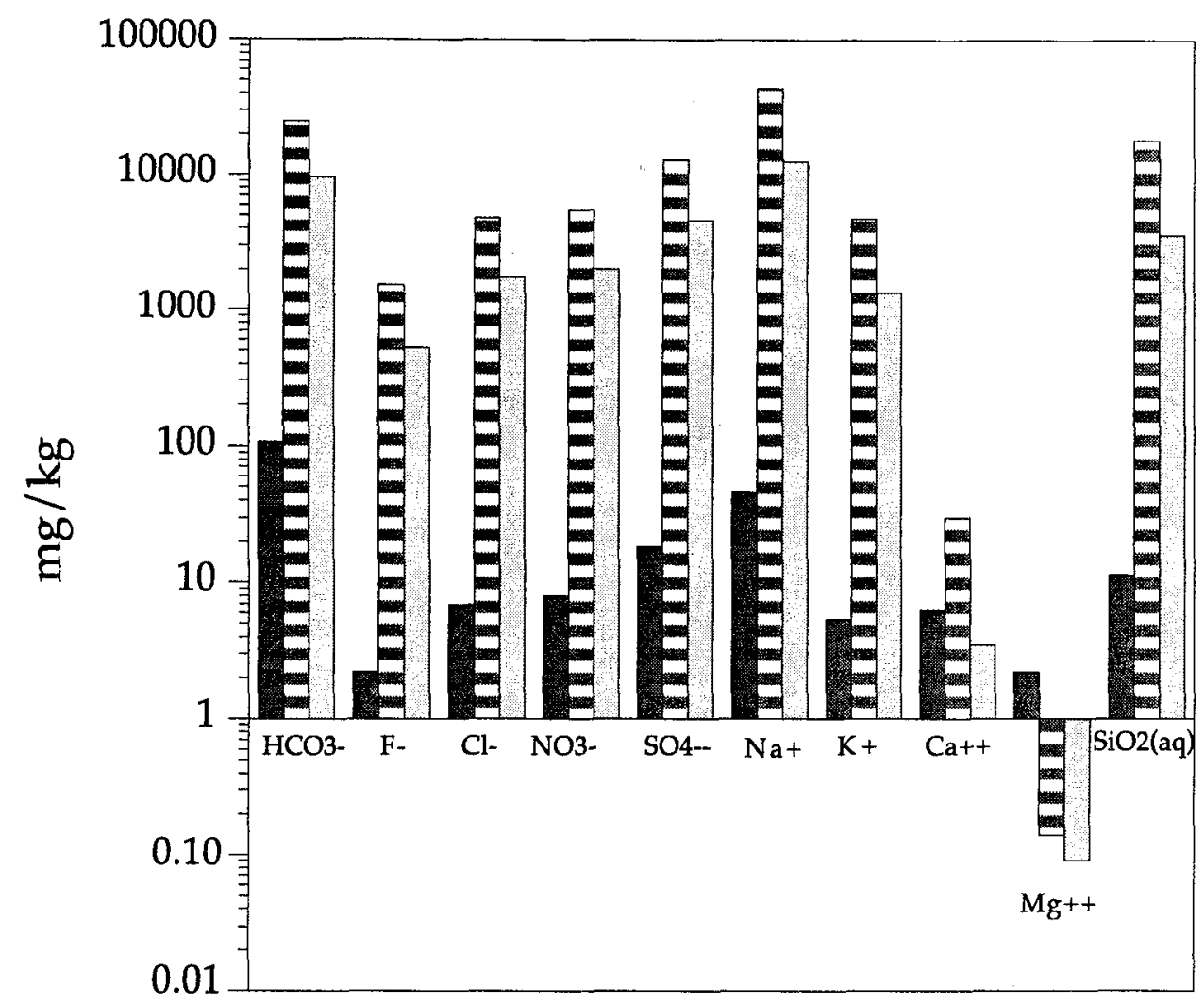

no tuff

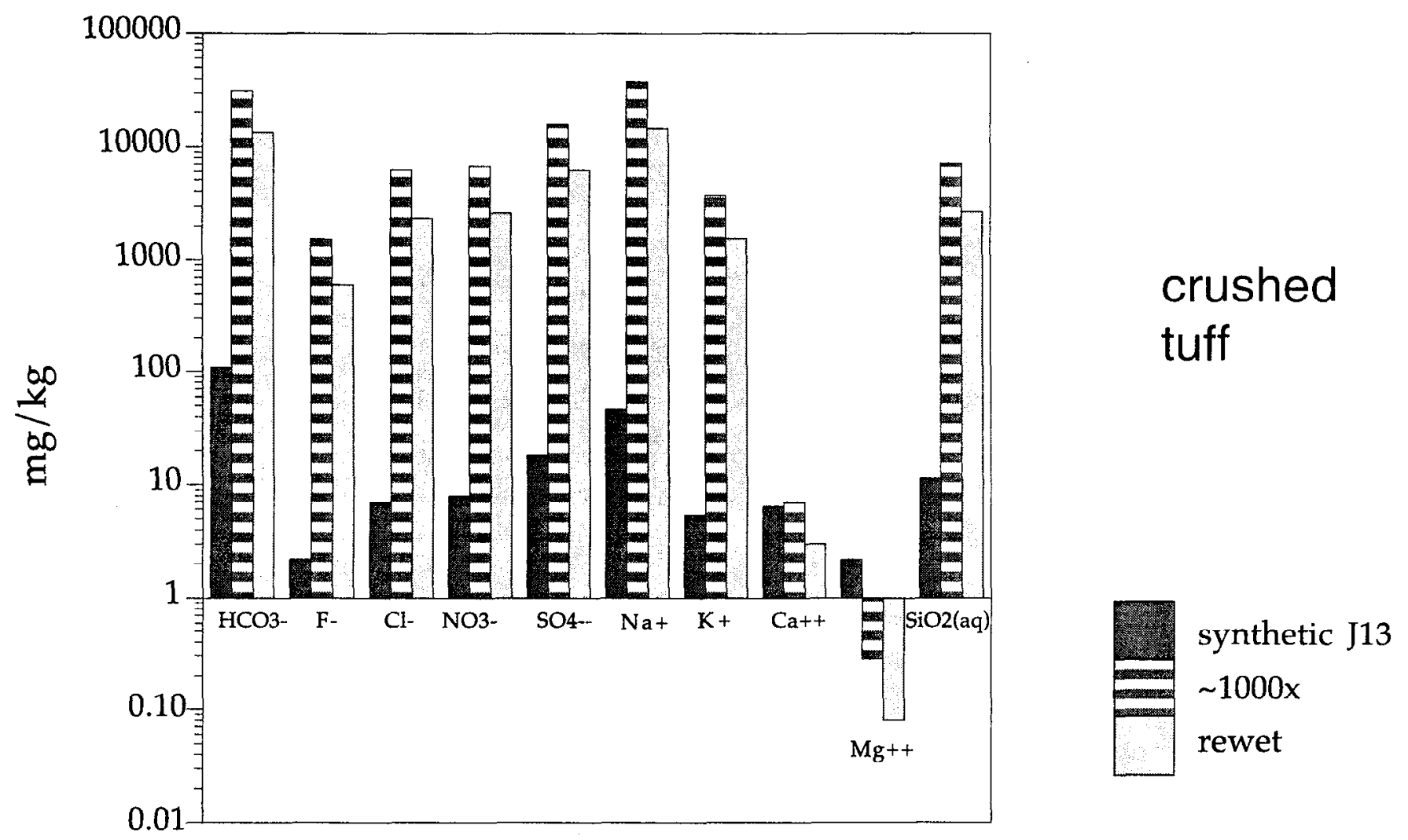

Fig. 2. Concentration of chemical species in synthetic J13 evaporation experiments. 


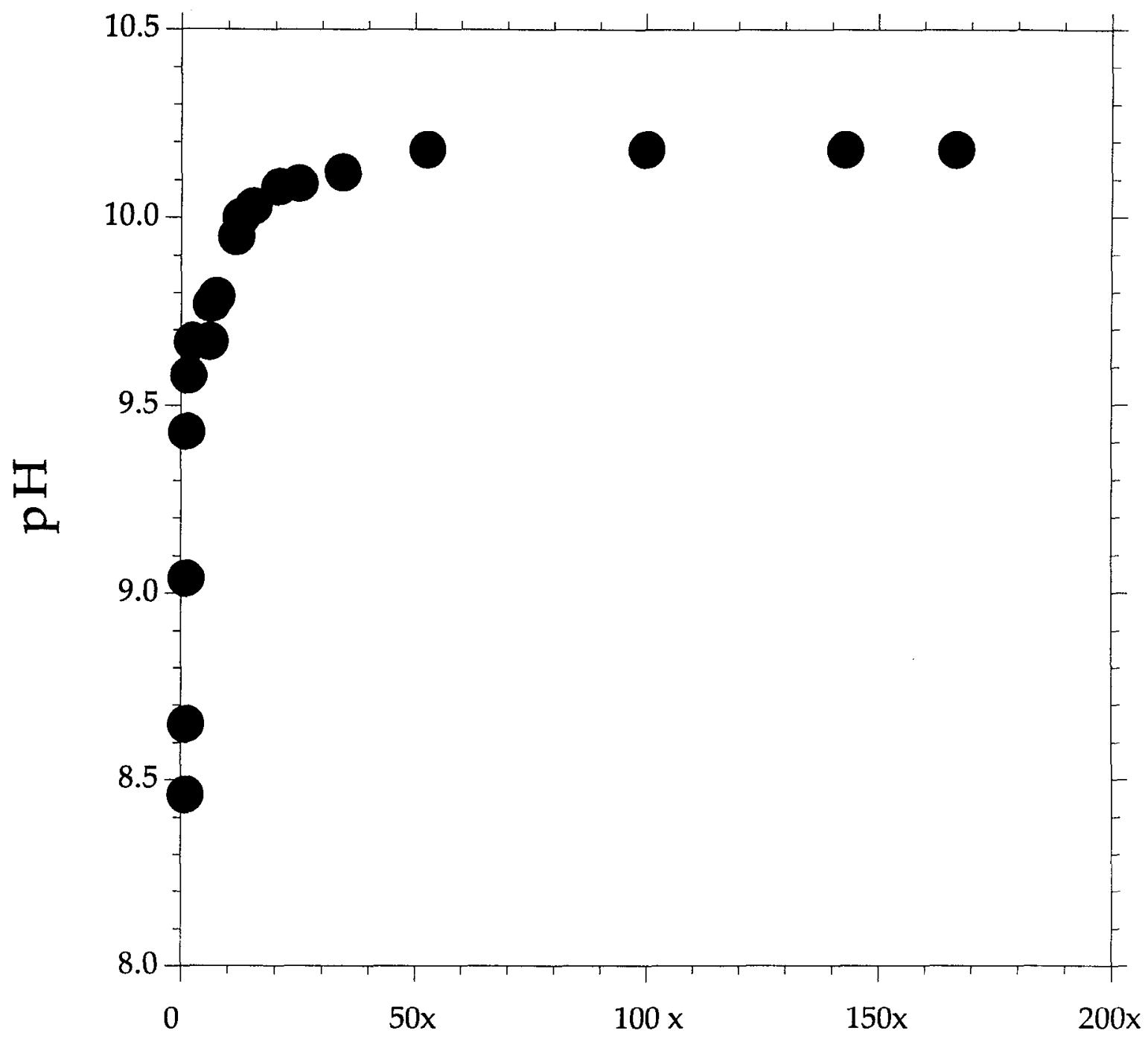

Fig. 3. $\mathrm{pH}$ vs. concentration factor for short-term evaporation experiment with $\mathrm{J} 13$ water alone. 

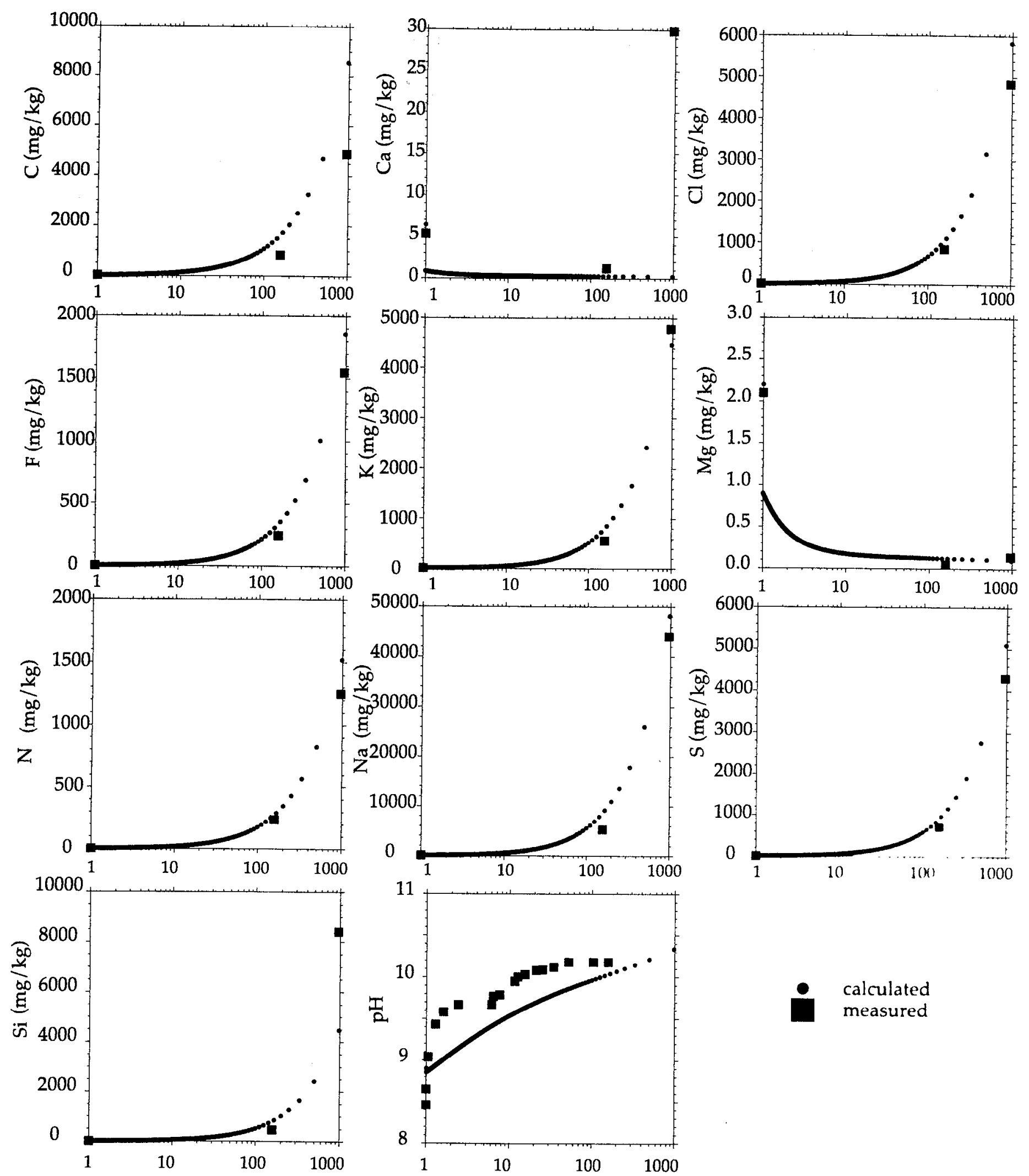

Fig. 4. Comparison of modeling results using com database and experimental data from the evaporation experiments with synthetic $\mathrm{J} 13$ water alone. Note that concentrations are given for elemental compositions and that the $\mathrm{x}$-axis, concentration factor, is on a log-scale. 


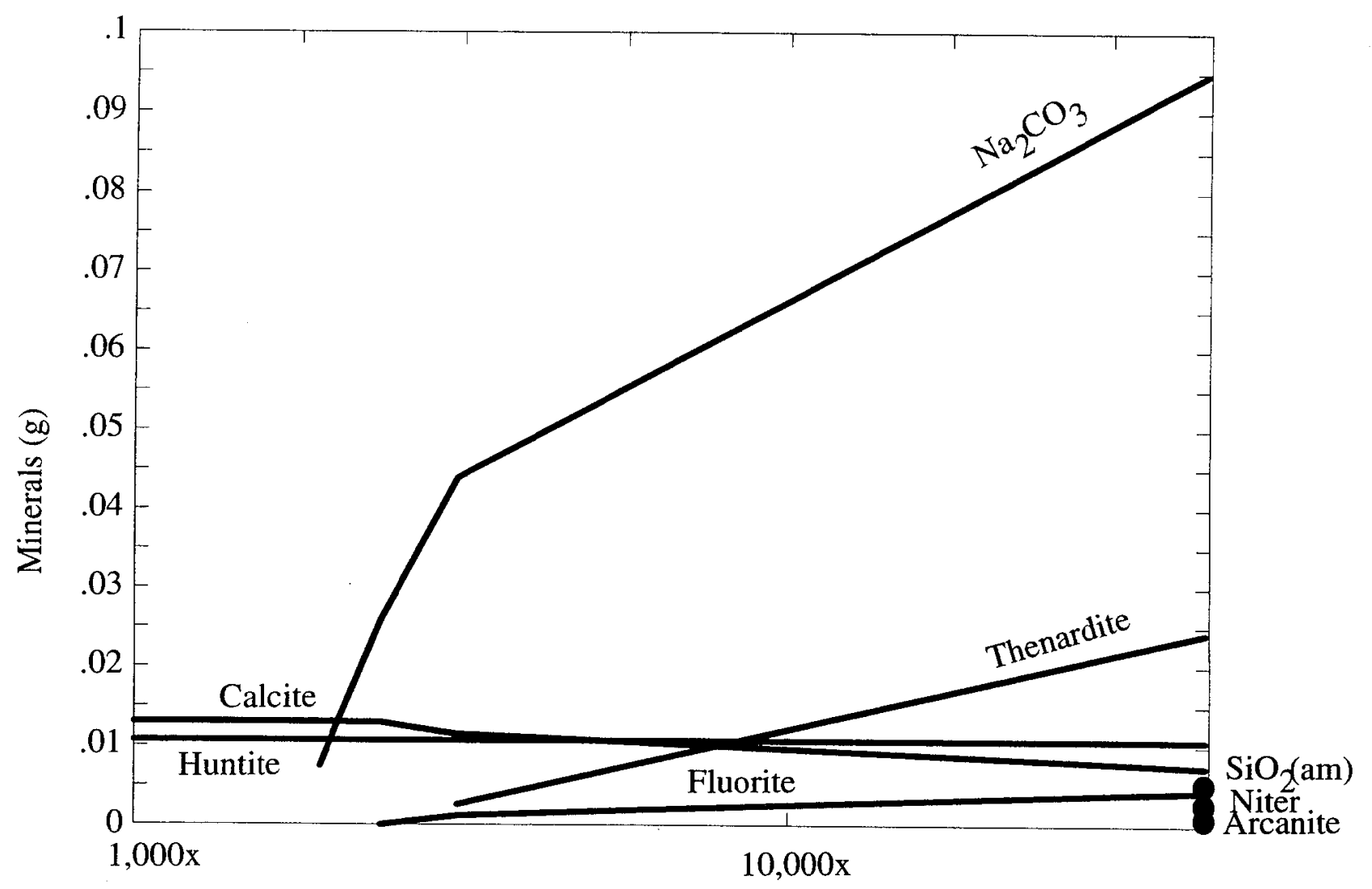

Fig. 5. Predicted mineralogical evolution during evaporation of synthetic J13 water alone, using com database. Note the $\mathrm{x}$-axis is a log-scale. 

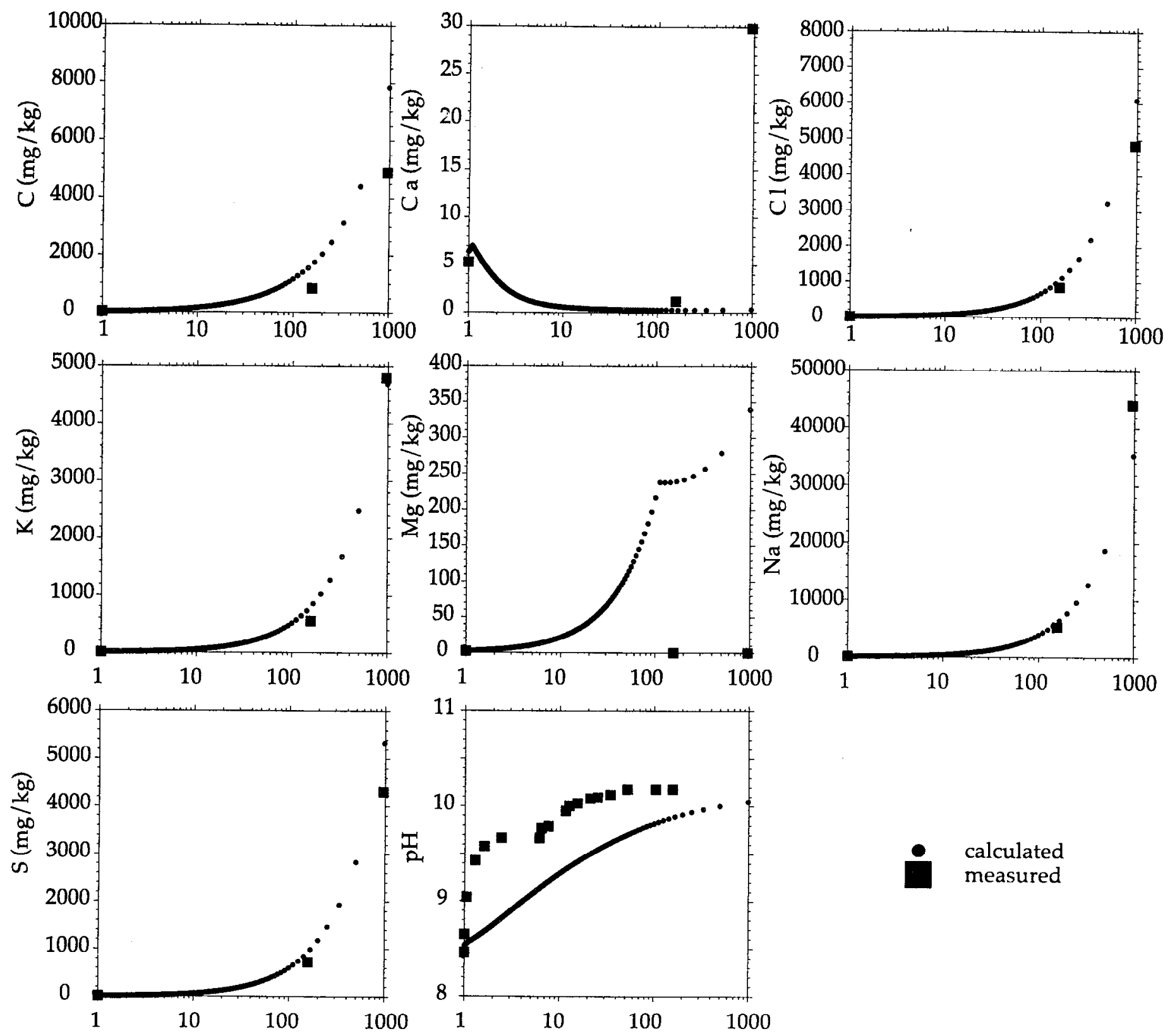

Fig. 6. Comparison of modeling results using hmw database and experimental data from the evaporation experiments with synthetic $\mathrm{J} 13$ watcr alone. Note that concentrations are given for elemental compositions, that the $\mathrm{x}$-axis, concentration factor, is on a log-scale, and that the hmw database does not contain data for elements F, N and $\mathrm{Si}$. 


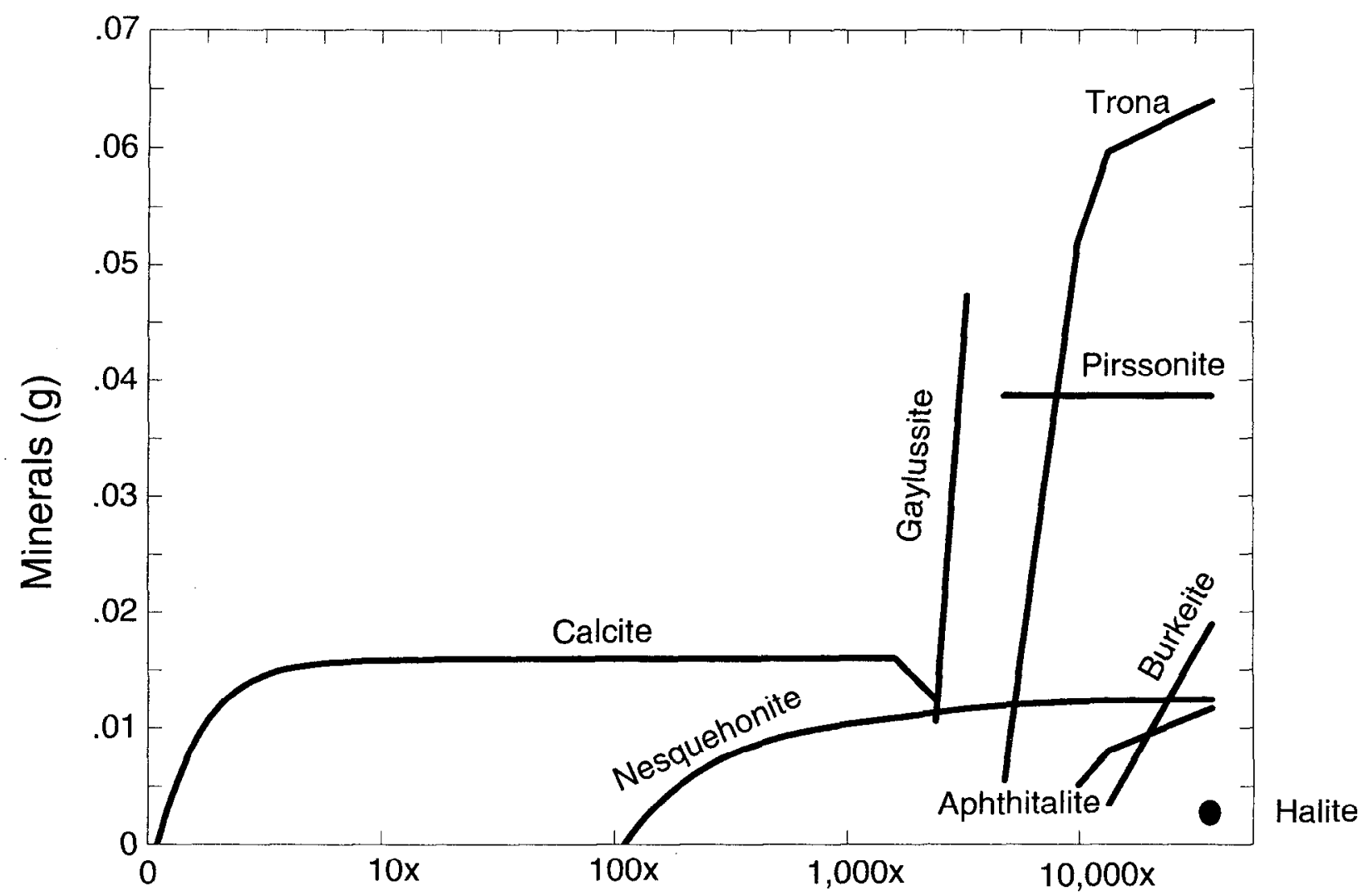

Fig. 7. Predicted mineralogical evolution during evaporation of synthetic J13 water alone, using hmw database. Note the $x$-axis is a log-scale. 

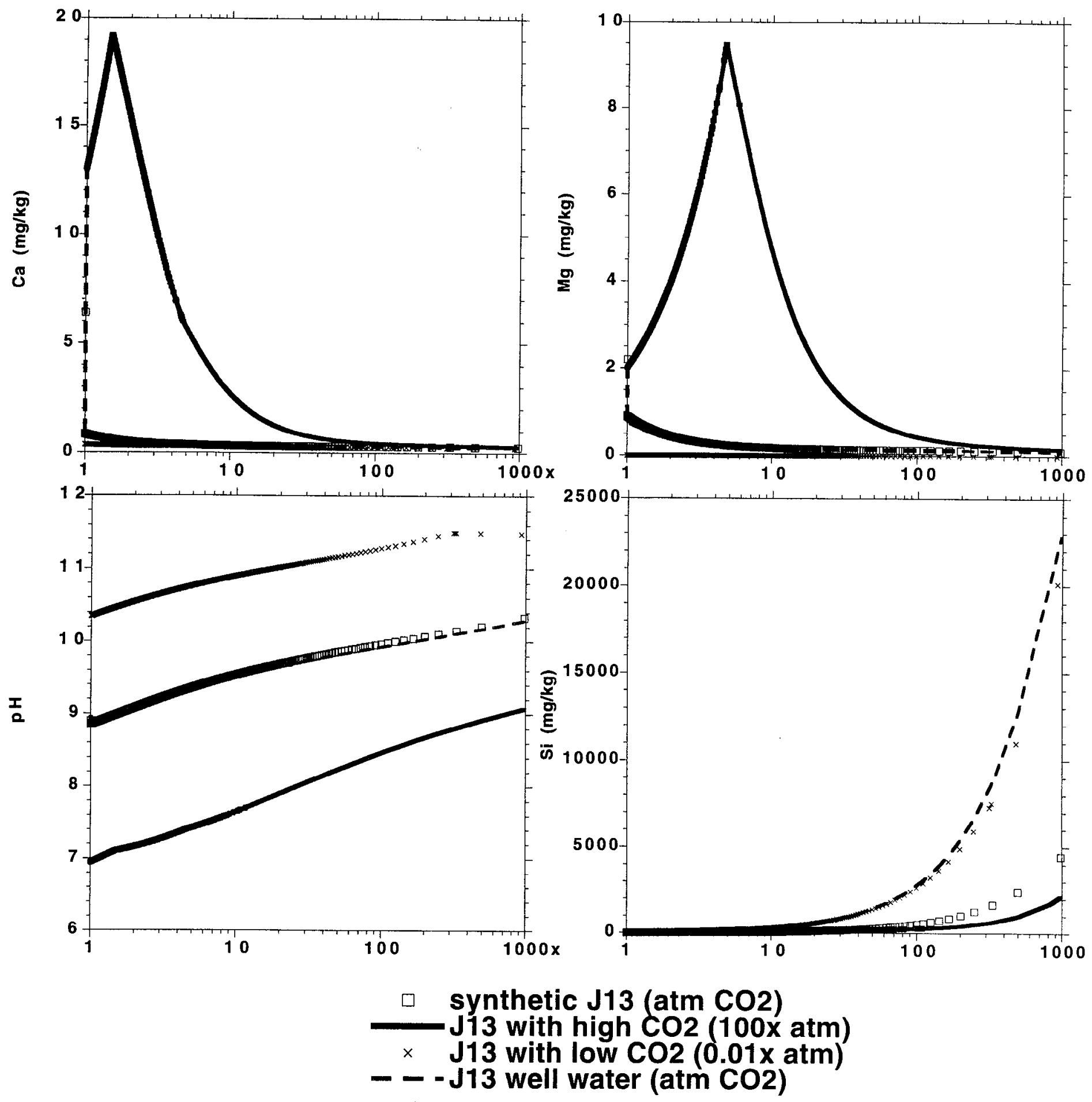

Fig. 8 Predicted evolution of fluid chemistry during evaporation of synthetic J13, actual J13 and $\mathrm{J} 13$ with high and low $\mathrm{CO} 2$ water compositions (com databsase). The $\mathrm{x}$-axis is a log-scale. When comparing solution concentrations, note that the mass of the concentrated solutions is slightly different for each case. 

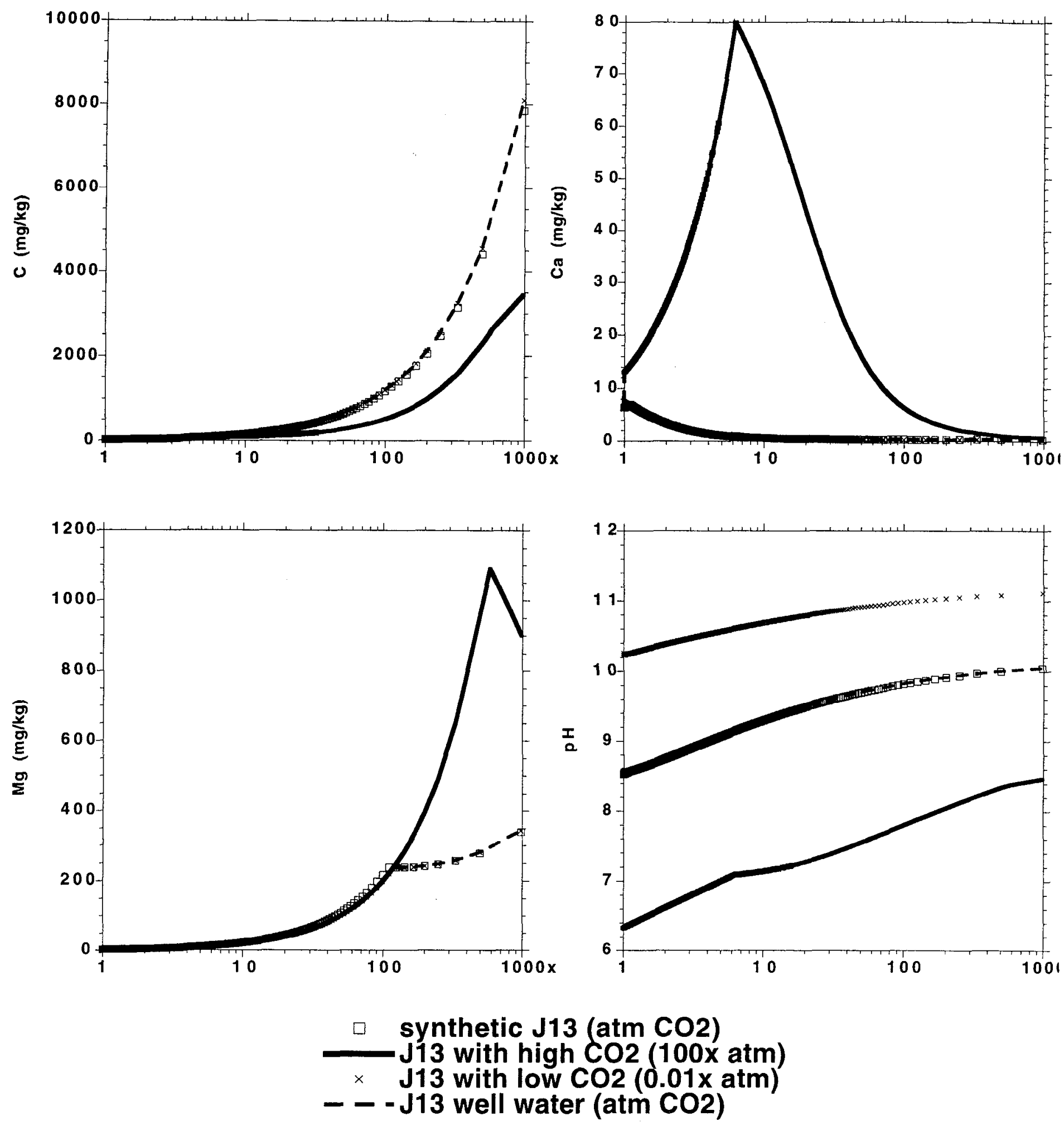

Fig. 9. Predicted evolution of fluid chemistry during evaporation of synthetic J13, actual J13 and $\mathrm{J} 13$ with high and low $\mathrm{CO} 2$ water compositions (hmw databsase). The $\mathrm{x}$-axis is a log-scale. When comparing solution concentrations, note that the mass of the concentrated solutions is slightly different for each case. 